\title{
Artificial intelligence in hospitals: providing a status quo of ethical considerations in academia to guide future research
}

\author{
Milad Mirbabaie ${ }^{1} \cdot$ Lennart Hofeditz ${ }^{2}$. Nicholas R. J. Frick ${ }^{2}$ - Stefan Stieglitz ${ }^{2}$
}

Received: 15 February 2021 / Accepted: 25 May 2021 / Published online: 28 June 2021

(c) The Author(s) 2021

\begin{abstract}
The application of artificial intelligence (AI) in hospitals yields many advantages but also confronts healthcare with ethical questions and challenges. While various disciplines have conducted specific research on the ethical considerations of AI in hospitals, the literature still requires a holistic overview. By conducting a systematic discourse approach highlighted by expert interviews with healthcare specialists, we identified the status quo of interdisciplinary research in academia on ethical considerations and dimensions of AI in hospitals. We found 15 fundamental manuscripts by constructing a citation network for the ethical discourse, and we extracted actionable principles and their relationships. We provide an agenda to guide academia, framed under the principles of biomedical ethics. We provide an understanding of the current ethical discourse of AI in clinical environments, identify where further research is pressingly needed, and discuss additional research questions that should be addressed. We also guide practitioners to acknowledge AI-related benefits in hospitals and to understand the related ethical concerns.
\end{abstract}

Keywords Artificial intelligence $\cdot$ Ethics $\cdot$ Healthcare $\cdot$ Hospitals $\cdot$ Discourse approach

\section{Introduction}

Ethical considerations are not limited to the philosophy discipline (e.g., Ploug and Holm 2020), but are also highly relevant in healthcare and social science-related disciplines such as information systems (IS) (e.g., Wang 2020). However, current developments in artificial intelligence (AI) give rise to profound novel ethical challenges when applied in healthcare, possibly posing a threat to patients (Jain et al. 1996; Rudin 2019; Mirbabaie et al. 2021a).

Milad Mirbabaie

milad.mirbabaie@uni-paderborn.de

Lennart Hofeditz

lennart.hofeditz@uni-due.de

Nicholas R. J. Frick

nicholas.frick@uni-due.de

Stefan Stieglitz

stefan.stieglitz@uni-due.de

1 Faculty of Business Administration and Economics, Paderborn University, Paderborn, Germany

2 Professional Communication in Electronic Media / Social Media, University of Duisburg-Essen, Duisburg, Germany
The implementation of AI recently became more distributed in hospitals worldwide (Knijnenburg and Willemsen 2016; Luger and Sellen 2016; Li et al. 2019b), creating discernible benefits assisting medical experts in hospitals (Rauschert et al. 2020; Rong et al. 2020). The term AI is usually associated with human-like behavior, but it must rather be considered as a ubiquitous concept (Siau and Wang 2018). Current applications have been developed for particular tasks (e.g., Frick et al. 2019a), such as taking advantage of medical data to generate predictions or derive recommendations (Krittanawong et al. 2017; Ku et al. 2019). For example, AI monitors patients' health conditions to support healing and regeneration (Pereira et al. 2013) and assists physicians in diagnosing diseases (Mirbabaie et al. 2021b) and planning suitable treatments (e.g., De Ramón Fernández et al. 2019; Li et al. 2019a, b; López-Martínez et al. 2019). However, some AI approaches possess certain technical restrictions which can lead to diagnostic results not being transferable to other circumstances or not being comprehensible to humans, i.e. remaining a black box (Anderson and Anderson 2007; Menai 2015; Knight 2017; Burton et al. 2019; Devi et al. 2019). Scholars and practitioners are also concerned with preventing inequitable usage and unfair information 
practices (Salerno et al. 2017; Sonja et al. 2018; LibaqueSáenz et al. 2020). Furthermore, AI still learns from medical data that is preprocessed by humans and thus might contain bias or prejudices (Kara et al. 2006; Hirschauer et al. 2015; Ploug and Holm 2020; Alami et al. 2020).

Enthusiasts claim strong reasons for the application of AI in hospitals (Ploug and Holm 2020); nevertheless, there are ominous threats possibly leading to AI becoming destructive (Arnold and Scheutz 2018). AI is a powerful but inscrutable tool unleashed with potential dubious effects for areas in which it is applied, e.g., healthcare and/or hospitals (Crawford and Calo 2016). Research on ethical considerations of $\mathrm{AI}$ in hospitals is no longer a mere part of science fiction but a real-world concern (Luxton 2014a, b). Despite existing studies on ethics of $\mathrm{AI}$ in healthcare (e.g., Alami et al. 2020; Arnold and Scheutz 2018; Ploug and Holm 2020), we argue that current research does not consider the growing significance of the topic in a diversified enough manner, but is rather narrowly focused on traditional explorations.

The current ethical discourse on AI is rather limited and usually presented in an unsystematic manner while also being conducted in separate disciplines (Brendel et al. 2021). There should instead be an increasing debate about ethical concerns (Porra et al. 2020) taking into account the multiple characteristics, principles, and dimensions of AI. Thus, our study follows a more holistic approach by identifying fundamental literature and pioneering works from diversified research domains. We aim to summarize ethical considerations into a research agenda for academia. Precisely, we intend to encourage the discourse on ethical considerations of $\mathrm{AI}$ in hospitals from an interdisciplinary perspective. We argue that this is of great interest to researchers and practitioners because the application of $\mathrm{AI}$ in hospitals is expected to increase heavily over the next decade and the impact on healthcare could be significant (Mirbabaie et al. 2021a).

Physicians still consider AI to be simple programs, tools, or algorithms that provide support in executing a certain task but they do not recognize (or even ignore) the fact that $\mathrm{AI}$ is capable of continuously learning and developing over time (Mitchell et al. 2018) and that it acts independently while delivering superior results compared to humans. There is an urgent demand for interdisciplinary research to comprehend the ongoing discourse on ethical considerations and dimensions of $\mathrm{AI}$ in hospitals and to understand the intricacies of this ever-evolving research area. By providing a holistic picture of ethical considerations and dimensions on AI in hospitals that are currently being researched, we aim to capture the current status quo and to guide pertinent future research directions. To address this urgent issue, our research is guided by the following research questions:

RQ1: What is the current discourse in academia and what are opinions of physicians regarding ethical considerations and dimensions of artificial intelligence in hospitals?
RQ2: What are future directions for interdisciplinary ethical research on artificial intelligence in hospitals?

We followed a modified discourse approach following the suggestions of Larsen et al. (2019) and identified as well as analyzed the domain ecosystem of ethical considerations and dimensions of $\mathrm{AI}$ in hospitals for a corpus construction. We thus performed descriptive research examining existing literature that describes the current situation (Bell 1989; Bear and Knobe 2016). In addition, we conducted semi-structured interviews with domain experts to further elaborate on and highlight related ethical challenges of AI in the clinical environment. This prescriptive approach contains implications and consequences as well as future recommendations (Bell 1989; Bear and Knobe 2016).

This paper contributes to theory by summarizing and structuring the status quo of recent research on ethical considerations and dimensions of AI in hospitals. Researchers will find the overview helpful to understand the current ethical discourse of $\mathrm{AI}$ in a hospital setting. To assist future investigations, we outline ethical constructs on AI in hospitals with which recent research is concerned. Furthermore, we outline an agenda explaining where further research is pressingly needed, and which questions need to be addressed. Practitioners will comprehend the differences between currently applied systems in hospitals and recent AI developments. Furthermore, medical specialists will be able to understand the extent to which $\mathrm{AI}$ is beneficial for clinical settings and the ways in which the stakeholders involved, i.e. physicians and patients, can benefit from its implementation. In terms of implications for society, readers will realize that $\mathrm{AI}$ is already used in hospitals and that its distribution continues to grow. Individuals will further understand that multiple issues regarding the application of $\mathrm{AI}$ in hospitals remain unaddressed.

\section{Literature background}

In this section, we start by explaining the concept of AI, followed by outlining illustrative examples of applications in hospitals. We then describe current ethical principles in healthcare, and finally, we illustrate ethical considerations associated with AI in hospitals.

\subsection{Al applications in hospitals}

Hospitals face a variety of issues that reduce the quality of care such as delayed patient flow or erroneous surgery scheduling (Ker et al. 2018; Bygstad et al. 2020). The introduction of AI might improve these types of common issues and yield sustainable advantages. This explains why medical research and practice are increasingly concerned with possible applications of AI (e.g., Bargshady et al. 2020; Jiang 
et al. 2017; Rauschert et al. 2020). AI is not a specific technology that is granted to a single discipline, but rather a collection of several concepts that constantly evolve (Barredo Arrieta et al. 2020). AI can generally be defined as "the ability of a machine to perform cognitive functions that we associate with human minds, such as perceiving, reasoning, learning, interacting with the environment, problem-solving, decision-making, and even demonstrating creativity" (Rai et al. 2019, p. iii). Simply put, AI aims to imitate human-like behavior (Krittanawong et al. 2017); however, current implementations are still far from achieving this goal (Brachten et al. 2020).

Applications of $\mathrm{AI}$ are rather narrowed down to a specific task (Batin et al. 2017; Frick et al. 2019b; Mirbabaie et al. 2020) but commonly generate superior results compared to humans. When integrated into the existing technical infrastructure of hospitals, AI accelerates data collection from multiple sources (Nasirian et al. 2017), provides medical experts with more accurate and timely information (Atherton et al. 2013; Preece et al. 2017; Diederich et al. 2019), tailors to the needs of patients and their treatment processes (Dilsizian and Siegel 2014) and enhances integration with other hospital IS (Serrano et al. 2020). AI continuously learns and develops over time by processing various types of medical information from multiple years of experience using divergent data sources (Mitchell et al. 2018). Conclusions are based on a larger sample size compared to those of medical professionals (Neill 2013) and AI is more likely to provide objective decisions. AI is also more likely to evaluate patients' conditions based on medical facts, as their systems do not rely on subjective impression, situations, emotions, or time of the day (Gnewuch et al. 2017; Seeber et al. 2020).

AI already supports multiple processes within hospitals. For example, AI guides patients with exercise promotion, medication adherence (Bickmore et al. 2010; King et al. 2013), chronic disease self-care management (Kimani et al. 2016), and daily diabetes routines (Shaked 2017) as well as accelerating the gathering of medical information in preparation for therapy and forwarding them to physicians (Denecke et al. 2018). In these examples, patients use AI in the form of a conversational agent (CA), intelligent systems that interact with and augment humans' abilities (Mirbabaie 2021). Interacting with CAs not only assists patients but also clinicians in the treatment of certain diseases.

AI also assists medical experts within disease diagnostics such as ectopic pregnancies (De Ramón Fernández et al. 2019), neonatal sepsis (López-Martínez et al. 2019), or coronary artery disease (Li et al. 2019a). Medical data are thereby processed, evaluated, and classified using AI algorithms to estimate probabilities and enable clinicians to detect diseases earlier, thus allowing them to treat patients more effectively. The implementation of information technologies such as AI can impact hospitals' revenue cycle management and consequent financial sustainability (Singh et al. 2021).

Even though existing endeavors provide justification for the use of $\mathrm{AI}$ in clinical environments, researchers and practitioners are frequently confronted with ethical questions eventually preventing possible applications due to the fear of causing unpredictable harm to patients. The discussion on autonomous driving showed that the expectations on AI can be even higher than towards human. The same could apply for the use of AI in hospitals and therefore need further examination.

\subsection{Ethical principles in healthcare}

Ethics is an interdisciplinary field of study and a complex concept that governs the accumulation and interplay of moral principles (Siau and Wang 2020). Moral principles describe norms for the behavior and actions of groups or individuals in a society (Nalini 2019) that guide entities (such as humans or intelligent robots) regarding what is right and wrong. Overall, it is tough to determine where ethical behaviors begin and where unethical behavior comes into play. As one approach to determine what is right and wrong, virtues can be considered. Virtue ethics is part of normative ethics and addresses the principles in which individuals believe (Siau and Wang 2020). Virtue ethics can be seen as an overarching moral principle to help make morally problematic decisions (such as which treatments should be provided in hospitals based on a diagnosis made by an $\mathrm{AI}$ ). In this study, we therefore focused on a virtue-ethical perspective regarding AI applications in hospitals, concentrating on treatment decisions.

Research on ethical considerations in healthcare is generally divided into three fields (Page 2012): the first field focuses on ethical developments of future healthcare experts throughout their medical training (Price et al. 1998; Bore et al. 2005). The second assesses individual ethical attitudes and how they differ among medical professions (Rezler et al. 1990, 1992). The third is concerned with the evaluation of ethical principles and their applications within treatment of patients (Hebert et al. 1992; Price et al. 1998). Ethical principles in medicine can be traced back to those of the physician Hippocrates (400 BCE), on which the concept of the Hippocratic oath is rooted (Miles 2005). The Hippocratic oath was a Greek document containing ethical standards for physicians which, for example, covers protecting the privacy of patients (Fox and James 2020). Today, the majority of medical graduates swear some kind of oath that is based on the Hippocratic oath (Hulkower 2010). Since its origin, various concepts have been developed for ethical guidelines for treating patients. The principles of biomedical ethics of Beauchamp and Childress (2019) have found great acceptance in medicine. The authors define four core principles 
of bioethics. (1) The principle of beneficence involves the expectation that healthcare professionals act in a way that benefits patients. (2) The principle of non-maleficence aims at avoiding any harm to involved individuals, i.e., patients or physicians. (3) The principle of autonomy respects the capabilities of individuals to make independent decisions. (4) The principle of justice specifies that all patients should be treated equally (Beauchamp and Childress 2019). Treatment ethics is intentionally defined rather broadly to allow room for individual considerations and prioritizations by physicians. Besides the principles of bioethics, ongoing research and practice are increasingly shaped by associations. There are country-specific organizations like the American Medical Association (USA) or the Academy for Ethics in Medicine (Germany), which define standards for honorable behavior of physicians when treating patients and encourage the scientific discourse on ethical questions in medicine (Riddick 2003; AEM 2020; AMA 2020). Furthermore, there are overarching institutions like the European Council of Medical Orders (CEOM 2020), which promote the practice of high-quality medicine in light of the patients' needs.

Despite the existence of ethical guidelines and principles for medical professionals, the entire healthcare system is regularly confronted with new ethical considerations. A recent example from Poland demonstrates that local governments affect healthcare and affect the majority of a population. The country's constitutional court declared abortions of children with malformations to be illegal (Amnesty International 2020). Besides restricting the freedom of choice of expectant parents, practicing physicians are restrained by this law and must abide even when an alternative decision might be more appropriate. Human rights activists and the Polish opposition heavily criticized the ruling of the constitutional court, arguing that illegal abortions will rise (Walker 2020). Another example of ethical considerations is the current discussion on distributing a potential COVID-19 vaccine. In principle, it seems reasonable that vaccinations should be given in a sequence based on profession. It is suggested, for example, that people in caring jobs should receive preferential treatment. Naturally, the question arises which professions within care should be prioritized, e.g., nursing, or elderly care?

The examples presented are intended to illustrate the idea that ethical principles are not only established by medical workers but are also heavily impacted by external forces. Likewise, AI applied in healthcare needs to adjust to a continuously changing environment with frequent interruptions (Wears and Berg 2005; Menschner et al. 2011; Rosen et al. 2018), while maintaining ethical principles to ensure the well-being of patients. Thus, in our study, we use the four core principles of biomedical ethics as suggested by Beauchamp and Childress (2019) as a conceptual categorization to classify our findings. This is then used to provide a research agenda for academia to examine the ethical challenges of using $\mathrm{AI}$ in hospitals.

\subsection{Ethical considerations of Al in hospitals}

Recent AI implementations in hospitals and in healthcare in general come with a variety of ethical considerations. For example, AI is associated with bias, discrimination, opacity, and rational concerns and intentions (e.g., Arnold and Scheutz 2018; Gruson et al. 2019; Ploug and Holm 2020) as much as it is associated with transparency, trust, responsibility, liability, and explainability (e.g., Alami et al. 2020; Wang 2020). A recent study by Ploug and Holm (2020) investigated the ethical concerns of AI for medical diagnostics and treatment planning. The authors argued that patients should be able to withdraw from being evaluated by AI because a trustful relationship between physicians and patients is essential for the success of the treatment process. Furthermore, Ploug and Holm (2020) explain that there are problems regarding bias and opacity for the patient, related implications for the entire healthcare sector, and rational concerns about impacts on society. Another study by Alami et al. (2020) provides a synthesis of key challenges posed by AI. Besides technological, organizational, and economic issues, the authors also raise several ethical obstacles. For example, AI applications can be distinguished between decision-support tools and decision-making tools. AI as decision-support tools assist medical specialists with specific tasks, e.g., within the diagnostic process (e.g., De Ramón Fernández et al. 2019; López-Martínez et al. 2019). When applied as a decision-making tool, AI will derive conclusions on its own without being supervised by physicians. However, it is yet to be defined who is held responsible for AI-based decisions leading to errors in the treatment process. Another issue illustrated by Alami et al. (2020) is the potential unexplainability of algorithmic outcomes, i.e. black box, posing a high risk to patients' well-being (Knight 2017; Rudin 2019). Of course, this makes it nearly impossible to build trust in the AI's decisions, especially when patients' lives are at stake.

Compared to ethical guidelines in healthcare, there are neither standardized regulations for the application of AI in healthcare nor in hospitals. However, most healthcare systems acknowledge the rapid development of AI for medical purposes (Duan et al. 2019) causing organizations and governments to define relevant ethical frameworks. For example, the European Union has developed the "European Ethics Guidelines for Trustworthy AI" defining its recommendations for trustworthy AI and key requirements for safety and for societal and environmental wellbeing (EU 2020). Furthermore, the World Health Organization has explained ethical challenges for the "global development and implementation of artificial intelligence 
systems in healthcare" (Bærøe et al. 2020, p. 261) and continually proposes suggestions for the ethical development and usage of AI. Besides global observations of AI within healthcare, research is equally concerned with deriving ethical principles, guidelines, and frameworks. For example, Floridi et al. (2018) developed an ethical framework for a good AI society based on the four core principles of bioethics of Beauchamp and Childress (2019). The authors added a fifth dimension explicability explaining the "need to understand and hold to account the decision-making processes of AI" (Floridi et al. 2018, p. 700).

Since the authors took an initial approach to tackle ethical issues regarding AI, we extended our conceptual categorization to include the principles of biomedical ethics of Beauchamp and Childress (2019) as well as the dimension of explicability (Floridi et al. 2018) which in most research is interchangeably used for explainability. We used these two pieces of work as the foundation of this work because they have been frequently cited and are centrally concerned with ethical dimensions of AI in various domains. Additionally, we used these frameworks because one includes a clear philosophical perspective on virtue ethics and both a bioethical perspective that is applicable to treatment ethics and the context of healthcare. Even though these articles did not focus on healthcare or hospitals themselves, the discussed ethical principles have been frequently used in other articles. Despite increasing studies being conducted on ethical considerations, current approaches are mostly congruent or very alike and focus on one specific discipline or a certain abstraction level. We thus argue that future endeavors would benefit from an alternative discourse from an interdisciplinary perspective that guides pertinent research directions.

\section{Research design}

Ethical discourses on the impact of new technologies are usually very unsystematic, as there is often no fundamental manuscript on which to base them. Although there have been some pioneering works, which are often quoted, many parallel discourses emerge, which make little reference to each other. In addition, ethical discourses are usually conducted separately in certain disciplines. To investigate how academia can contribute to the responsible use of $\mathrm{AI}$ in digital health and practical health in hospitals, we identified fundamental manuscripts following adapted version of the discourse approach proposed by Larsen et al (2019). Based on this, we identified ethical principles and their relationships and highlighted these via expert interviews with hospitals physicians and other decision-makers in hospitals.

\subsection{Modified discourse approach}

For systematic literature analysis, new approaches are constantly being developed (vom Brocke et al. 2009, 2015). However, with the increasing number of publications, it is becoming more and more difficult to find a method that can provide a comprehensive picture of a discourse. The discourse approach is an instrument that creates a citation network based on fundamental manuscripts of a theory, a model, a framework, or a research domain (Larsen et al. 2019). It starts with the identification of fundamental theorybuilding papers (L1), followed by theory-contributing and other papers that cite these L1 papers (L2). In a last step, papers are identified by means of citations, which influenced the L2 papers (L3). Larsen et al. (2019) call the sum of these L1, L2, and L3 papers "the theory ecosystem."

However, it is not always obvious which manuscripts form the fundamental basis for a discourse. The discourse on the responsible use of $\mathrm{AI}$ in hospitals is a rather new one, as fundamental manuscripts have yet to emerge. Therefore, the discourse approach cannot always be applied exactly according to Larsen et al. (2019). We therefore propose a modified discourse approach. The aim of our approach is to start vice versa by identifying fundamental L1 manuscripts and to derive a research agenda for ethical considerations of AI in hospitals. As the IS perspective is rather interdisciplinary, we started our research to the field of IS and related disciplines using the litbaskets.io database with 3XL search. Our method consisted of four phases following the recommendations by Larsen et al. (2019) and highlighting the outcomes with interview findings. An overview of the applied research approach is provided in Fig. 1 and will be presented in the following sub-sections.

\subsubsection{Boundary identification}

A research domain is less a set of characteristics and more an evolving discourse between scholars (Larsen et al. 2019). To reflect this discourse, a starting point is first required. According to Larsen et al. (2019), this initial point is the origin of a theory, framework, or model. In this paper, however, we wanted to identify the status quo in research on ethical considerations on AI use in hospitals. Therefore, we based our boundary identification on elements of other systematic literature reviews such as a comprehensive keyword search as proposed by vom Brocke et al. (2015). To identify a first sample in the theory ecosystem, we first collected frequent keywords related to ethical principles of using AI in health and especially in hospitals. We selected artificial intelligence as the keywords as well as related terms that focus on more anthropomorphic forms of AI, because our focus was on technology that is also perceived as an AI by both the physicians and the patients. In addition, we selected ethic* and 


\begin{tabular}{|c|c|}
\hline $\begin{array}{l}\text { a) } \\
\text { b) } \\
\text { c) }\end{array}$ & $\begin{array}{l}\text { Step 1: Boundary identification } \\
\text { Identification of keywords from the domain } \\
\text { Definition of a suitable and broad research string } \\
\text { Deleting of duplicates within the results }\end{array}$ \\
\hline & Large sample of theory ecosystem identified \\
\hline $\begin{array}{l}\text { a) } \\
\text { b) } \\
\text { c) }\end{array}$ & $\begin{array}{l}\text { Step 2: Corpus construction } \\
\text { Manually coding of each manuscript according to reasonable inclusion and exclusion criteria (using multiple coders) } \\
\text { Copying of the references (RI) from every identified manuscript into one spreadsheet } \\
\text { Ranking of the identified articles (the references of the original manuscripts) according to their number of citations }\end{array}$ \\
\hline & Most cited manuscripts identified \\
\hline $\begin{array}{l}\text { b) } \\
\text { c) } \\
\text { d) }\end{array}$ & $\begin{array}{l}\text { Step 3: The MDID technique } \\
\text { Dividing the number of citations of each paper (RI) by the number of years that have passed since the release }(2020 \\
\text { included) } \\
\text { Assign the result to the list of the manuscripts (RI) with a score between } 0 \text { and } 3 \\
\text { Determining of the most impactful manuscripts (within } R I) \text { considering every manuscript with a value }>I \\
\text { Reading and analyzing of the identified manuscripts (RI) and manually creation of a citation network }\end{array}$ \\
\hline & Fundamental manuscripts identified \\
\hline $\begin{array}{l}\text { a) } \\
\text { b) } \\
\text { c) } \\
\text { d) }\end{array}$ & $\begin{array}{l}\text { Step 4: Discourse evaluation } \\
\text { Content analysis of the manuscripts' discussion and conclusions (e.g. classification if constructs) } \\
\text { Deriving of expert interview guideline based on the content analysis } \\
\text { Conducting expert interviews with physicians to highlight the findings } \\
\text { Revision of content analysis and identification of research gaps }\end{array}$ \\
\hline
\end{tabular}

Fig. 1 Adapted discourse approach based on Larsen et al. (2019) to derive a research agenda

moral* as relevant keywords because they most precisely represented what we wanted to examine from a philosophical point of view. Furthermore, we selected common terms from the area of digital health. Afterwards we formulated a broad and comprehensive search string including the following terms:

(AI or "artificial intelligence" or "chatbot*" or "chatbot*" or "conversational agent*" or "digital assistant*" or "virtual assistant*" or "personal assistant*" or "virtual agent*" or "ai-based system*") AND (health or "health care" or healthcare or "digital health" or "hospital*" or medicine or medical) AND ("ethic*" or "moral*")

We applied the search string on Scopus and used litbaskets.io (3XL search) to receive an interdisciplinary focused sample of manuscripts (Boell and Blair 2019). In addition, we manually searched for high-ranked conference articles (in International Conferences on Information Systems, European Conference on Information Systems, Hawaii International Conference on Systems Sciences, Americas
Conference on Information Systems, Pacific Conference on Information Systems, Australasian Conference on Information Systems, and the German Wirtschaftsinformatik). In our initial sample, we focused on IS publications since our aim was to visualize and reflect the interdisciplinary discourse. However, as a basic search is not capable of providing a holistic overview, and we were also interested in retrieving literature outside the IS discipline, we conducted both a backward and forward search. In the backward search, we gathered the reference lists in the bibliographies of all the papers from the initial search and assessed their relevance regarding our research goal. Within the forward search, we considered every paper identified in the previous steps and analyzed literature that cited these identified papers after their initial publication. We thus expanded our search to other scientific domains and outlets. For example, we identified publications from healthcare (e.g., Journal of the American Medical Association) and philosophy (e.g., Philosophical Transactions of the Royal Society).

We conducted our literature search between September and October of 2020. After removing duplicates from the 
results, we identified 104 manuscripts as our initial sample. This sample consisted of interdisciplinary journals and highlevel conference articles and was labeled as potential L2 articles (Larsen et al. 2019) who cite the fundamental manuscripts of the discourse on the ethical use of $\mathrm{AI}$ in healthcare.

\subsubsection{Corpus construction}

As a next step, we investigated the identified literature in more detail. Our aim was to understand the discourse on the ethical dimensions of $\mathrm{AI}$ in healthcare and especially in hospitals. We, therefore, manually scanned the 104 identified manuscripts according to their topic relevance. We excluded papers that did not directly address ethical dimensions and articles that did not address AI or AI-related technologies. We included manuscripts that covered both ethics and AI. Two experienced coders created a codebook and applied the exclusion and inclusion criteria to the manuscripts from the first search, following a title, abstract, and keyword scan method. This led us to 60 manuscripts that we considered the most relevant for the ethical discourse on $\mathrm{AI}$ in healthcare.

However, we knew that not all relevant articles for a discourse can be identified by a keyword search (Larsen et al. 2019). If a keyword search is too broad, it can lead to a list containing far more manuscripts than is practical to read; and if a keyword search is too narrow, that can result in missing highly relevant articles. To address these issues, we copied all references from these 60 manuscripts into one list, which led us to 2433 references. As our aim was to identify fundamental manuscripts for the ethical discourse on $\mathrm{AI}$ in healthcare, we ranked those references according to how often they were cited in the initially identified papers. The number of citations per paper within the list of all references is shown in Table 4 in the "Appendix".

\subsubsection{Identification of fundamental manuscripts for the ethical discourse on Al in healthcare}

Although the number of citations is an important indicator to measure the relevance of a manuscript within a discourse (Larsen et al. 2019), the time span between the publications also needs to be considered. To take publication time spans into account, we propose a manual detection of implicit domain (MDID) technique. We divided the number of citations of each paper by the number of years that have passed since the date of publication. This resulted in a score between 0 and 3 citations per year within the identified corpus. This score does not represent the overall citations per year of the manuscripts, but rather the number of times they were cited per year within the 60 papers that we identified as relevant for the ethical discourse on AI in healthcare. Among those, a few papers had a score $>1$ and most of the papers scored lower than 1 . The score describes the impact and relevance of the manuscript on the current discourse on AI in healthcare. To better understand the distribution of the scores, we visualized the dissemination of the scores in a graph. We found that there was a small group of manuscripts that stood out and scored higher than the majority of the articles. We identified these papers due to the visible threshold in the graph. This small group of papers scored 1.3 or higher and consisted of only 15 manuscripts. In addition, we manually scanned how these manuscripts were cited within the identified corpus of 60 papers to ensure that they were not only mentioned as a side note. We considered all of these 15 manuscripts as the fundamental articles. Additionally, these 15 manuscripts came closest to what Larsen et al. (2019) had described as L1 manuscripts. Those manuscripts are listed in Table 1.

As our aim was to understand and structure the ethical discourse on $\mathrm{AI}$ in hospitals, we further analyzed those manuscripts manually and created a citation network (Fig. 2). We scanned the manuscripts for common patterns and extracted the ethical principles for using $\mathrm{AI}$ in hospitals to provide a research agenda for academia.

\subsection{Expert interviews}

Besides using the discourse approach as a fruitful method to obtain a comprehensive picture of the knowledge within a certain domain (Larsen et al. 2019), we also conducted semistructured expert interviews to highlight and underpin our findings. Expert interviews preserve knowledge from individuals with advanced experience in the research domain under investigation (Meuser and Nagel 2009). We thus initially defined criteria to find appropriate participants. Since discussions on

Table 1 Identified fundamental manuscripts of the discourse on the ethical use of $\mathrm{AI}$ in healthcare

\begin{tabular}{lll}
\hline Authors & Count & Score \\
\hline Vayena et al. (2018) & 8 & 2.667 \\
Ting et al. (2017) & 8 & 2 \\
Char et al. (2018) & 6 & 2 \\
McKinney et al. (2020) & 2 & 2 \\
Zeng et al. (2019) & 2 & 2 \\
Yu et al. (2018) & 5 & 1.667 \\
Gulshan et al. (2016) & 8 & 1.6 \\
Reddy et al. (2019) & 3 & 1.5 \\
Yu and Kohane (2019) & 3 & 1.5 \\
Schiff and Borenstein (2016) & 3 & 1.5 \\
Parikh et al. (2019) & 3 & 1.5 \\
Luxton (2019) & 3 & 1.5 \\
He et al. (2019) & 3 & 1.5 \\
Froomkin et al. (2019) & 3 & 1.5 \\
Cath (2018) & 4 & 1.334
\end{tabular}




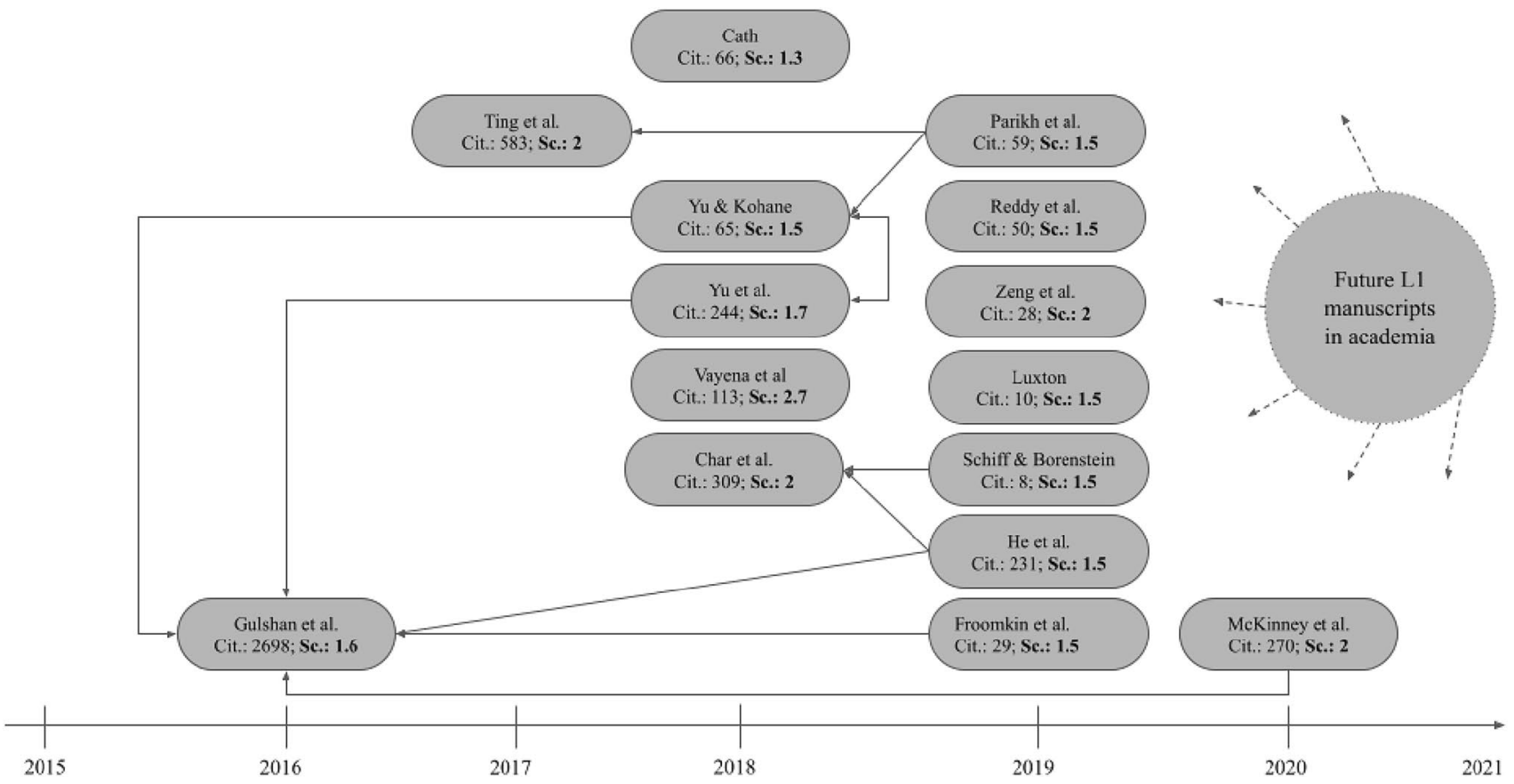

Fig. 2 Citation network of the 15 fundamental manuscripts

ethics in medicine are as ancient as the discipline itself, we intended to gain a holistic overview from experts of varying age groups. We further searched for medical experts working in hospital clinics who are frequently confronted with ethical questions impacting the well-being of patients. Following the recommendation of Creswell and Creswell (2018), three to ten individuals should be included for qualitative research. Moreover, we use the interviews to elaborate on and highlight our findings rather than to validate a theory. In total, we conducted six expert interviews with doctors and senior level experts in the context of hospital digitization from different medical disciplines. We interviewed one physician from obstetric care (resident doctor) and three surgeons from cranio-maxillofacial surgery (two senior physicians and one resident doctor). In addition, we spoke with a chief physician from a large hospital and a head of corporate communication with experience in digitization and change management in hospitals. An overview of our sample is outlined in Table 2 . To guarantee anonymity of our interviewees, we used the synonyms E1-E6 in the following sections.

We used an open interview technique to provide the experts with enough room to elaborate on their subjective beliefs and experiences (Meuser and Nagel 2009). We structured the interview with a prefixed guideline (Table 6 in the "Appendix") with central questions referring to our research question (Qu and Dumay 2011). Initially, we described the interview process to the interviewee, including a short briefing of the study and the rights of the participants, followed

Table 2 Sample overview of expert interviews with physicians and senior level experts

\begin{tabular}{|c|c|c|c|c|c|c|c|}
\hline Interviewee & Gender & Age & Tenure (years) & Position & Discipline & Hospital & Duration \\
\hline $\mathrm{E} 1$ & $\mathrm{f}$ & 31 & 3.5 & Resident doctor & Obstetric care & $\begin{array}{l}\text { University Hospital of Frankfurt, } \\
\text { Germany }\end{array}$ & $28: 17$ \\
\hline E2 & $\mathrm{f}$ & 38 & 7 & Senior physician & Cranio-maxillofacial surgery & $\begin{array}{l}\text { University Hospital of Dusseldorf, } \\
\text { Germany }\end{array}$ & $31: 38$ \\
\hline E3 & $\mathrm{f}$ & 35 & 5 & Senior physician & Cranio-maxillofacial surgery & $\begin{array}{l}\text { University Hospital of Dusseldorf, } \\
\text { Germany }\end{array}$ & $30: 30$ \\
\hline $\mathrm{E} 4$ & $\mathrm{f}$ & 31 & 2 & Resident doctor & Cranio-maxillofacial surgery & $\begin{array}{l}\text { University Hospital of Dusseldorf, } \\
\text { Germany }\end{array}$ & $35: 42$ \\
\hline E5 & $\mathrm{m}$ & 67 & 20 & Chief physician & Anesthesia & Retired & $42: 33$ \\
\hline E6 & $\mathrm{m}$ & 44 & 17 & $\begin{array}{l}\text { Head of Corpo- } \\
\text { rate Communi- } \\
\text { cations }\end{array}$ & Digitization Think Tank & Clinical Center Dortmund, Germany & $32: 41$ \\
\hline
\end{tabular}


by a verbal consent to the interview being recorded. In the first official phase, we asked general questions on the expert's characteristics, current position, and duties within the practicing discipline. This helped us to understand the clinical environment of the expert while making the interviewee comfortable with the interview situation. The second phase served as a foundation to comprehend which ethical considerations physicians are confronted with and whether they follow a certain codex. Within the third phase, we asked question on what ethical problems technology in general might cause and how they are capable of resolving ethical issues. The fourth phase began by asking interviewees what they associate with AI. After receiving their answers, we provided a definition of AI to achieve the same level of knowledge among all participants for the remainder of the interview. We then asked specific questions about the application of AI in hospitals, e.g., how AI might support clinical processes, which factors are crucial for successful deployment, and which ethical guidelines AI must follow. In the fifth phase, the participants were asked to elaborate on future ways in which AI implementations in hospitals could improve the clinical procedures. The interview concluded by providing the interviewee with a chance to ask further questions or to provide additional information, followed by a debriefing by the interviewer.

The data were collected between September and October of 2020 by two researchers. As this period was still strongly influenced by the COVID-19 pandemic, all interviews were conducted via a virtual call. As we were not interested in the expert's substantive statements rather than physical gestures or facial expressions, we recorded the audio and not the video signal and, respecting data privacy protection, deleted the recordings once the analysis of the interview was finished. For the examination of the retrieved data, we conducted a qualitative assessment of content analysis as previously proposed (Schilling 2006). This helped us to reduce the volume of the data by removing unnecessary words to form short and concise sentences. We paraphrased the experts' explanations by carefully listening to each interview recording, then further generalized and reduced the contents, leading to comprehensive statements.

The analysis of the data was performed using a thematic analysis where paraphrasing was done shortly after the interviews were conducted. We derived deductive categories based on the constructs as identified from the discourse approach and used them as clusters (Glaser 2013). We thereby intended to obtain an understanding of the status quo and prospective orientations. This research approach can be classified as a descriptive-prescriptive procedure because experts described the situation, e.g., what has happened or what is happening now and what should happen in the future (Bear and Knobe 2016). Following the recommendations of (Gioia et al. 2013), we used short paragraphs or sentences as coding units, i.e. open coding.
We used simple phrases or in vivo (second-order themes) to code the data, then categorized them under the constructs from the discourse approach (first-order theme). The coding process was collaboratively done by two researchers to distribute the effort of the analysis process, prevent a unilateral view of the data, and ensure intercoder reliability. Since the expert interviews were conducted with German participants working in German hospitals, the excerpts have been translated into English for the reader's understanding.

\section{Results}

We were able to identify 15 manuscripts that we could classify as fundamental by means of our modified discourse approach. The manuscripts were mostly published in medical journals, Nature, or Science (He et al. 2019; Parikh et al. 2019; Yu and Kohane 2019; McKinney et al. 2020). Among the papers, we found theoretical papers as well as empirical papers. Many manuscripts established principles for the ethical use of $\mathrm{AI}$ in hospitals or discussed different fields of application or types of AI. Although principles were strongly intertwined and we perceived some overlaps when directly comparing definitions between some papers, we could extract 18 unique ethical principles from the literature following Suddaby (2011). We consider these principles as mutually exclusive as they differed in their descriptions when comparing the 15 fundamental manuscripts. We classified the findings of our interviews into the four first-order themes beneficence, non-maleficence, justice, and autonomy and into the $18 \mathrm{~s}$ s-order themes which represent the principles in Table 3 .

One of the most mentioned ethical principles for using AI in healthcare was the principle of transparency (Cath 2018; Vayena et al. 2018; Zeng et al. 2019; Froomkin et al. 2019; He et al. 2019). It describes the visibility of the general logic of machine learning algorithms (Vayena et al. 2018). On the one hand, it is intertwined with the principles of explainability and explicability, which aim to not only make the algorithms transparent but also provide information for people with less technical knowledge such as patients or doctors (Cath 2018). Moreover, it seemed that explainability and transparency overlap and relate to similar issues. However, main difference between transparency and explainability is that transparency does not necessarily include further instructions such as a tutorial on how AI executes certain processes. If a hospital would provide access to the code of a system, they would provide transparency for this code; but to provide explainability, the code would need to be delivered with further explanation of its purpose and process. On the other hand, transparency is intertwined with the principle of fairness (Zeng et al. 2019). Zeng et al. (2019) stated that people in the context of healthcare might ask for transparency regarding the decision-making process of an AI out 


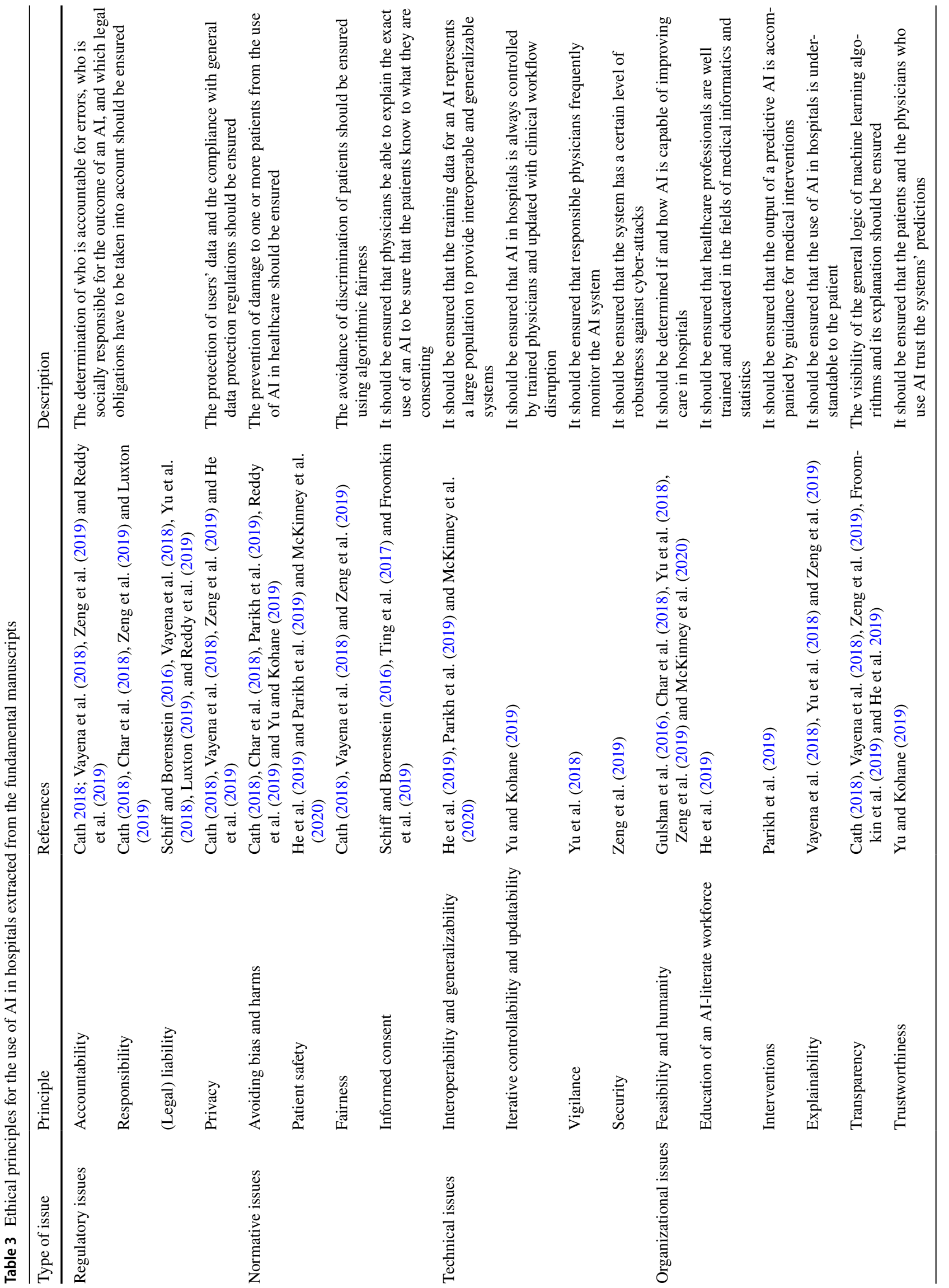


of concerns about fairness. However, we found no clear definition of what exactly fairness would mean in terms of $\mathrm{AI}$ and algorithms. We identified indications that in most fundamental manuscripts, the authors understand fairness as algorithmic fairness that ensures that there is no discrimination of minorities (Cath 2018). The results of the expert interviews confirmed the major relevance of transparency as an ethical principle. This especially refers to disclosing to medical experts how AI derives certain results. One expert clarified "I don't know if that is possible, but I should ideally understand what the $\mathrm{AI}$ is doing" (E4).

In addition to transparent communication about the presence of an AI, the liability must be clearly evident (Vayena et al. 2018). The principle of liability is closely linked to accountability and responsibility (Schiff and Borenstein 2016; Reddy et al. 2019). We summarized those three terms using responsibility as it was the most frequent and interchangeably used term within the considered literature. Accountability for errors that occur through AI use in hospitals has not yet been conclusively determined. One interviewee compared this to the debate on self-driving cars: "This reminds me of the debate about self-driving cars. It is unclear who is responsible. The car manufacturer? The insurance company? The software manufacturer? The driver? This has not yet been conclusively clarified with regard to AI in hospitals either" (E6). Liability can be defined as the legally obligated determination of who is morally responsible for medical errors regarding the use of AI (Schiff and Borenstein 2016). While liability tends to address the legal aspects, accountability is more focused on the authority to issue instructions. Responsibility, on the other hand, includes an ethical and social component and addresses the questions of how much indirect responsibility is relevant and which actors are indirectly responsible. However, liability, responsibility, and accountability are not clearly delineated in most of the fundamental works and need further definitions, clarifications, and delimitations (Reddy et al. 2019). While the terms are often used synonymously, they can also sometimes be used too narrowly. In a case study, Luxton (2019) examined the ethical, responsible, and legal liability issues surrounding the use of IBM Watson in hospitals. They provided a guide for physicians who want to use AI tools in hospitals and identified precautions based on a case where patients with leukemia should be treated. The interviews revealed that while AI can be helpful in making suggestions, medical experts should be responsible for health-related decisions. One expert summarized "the human emotional aspects are simply missing. AI simply cannot consider every human aspect" (E3). Another expert added that "physicians possess numerous years of experience. Subjective human impressions might positively influence the treatment. There is still quite some information that an AI does not or cannot have." (E6). Mentioned examples included the family background or health insurance.

Another reason why transparency regarding how algorithms work is highly ethically relevant is that the training dataset of an AI can influence the system's output (Parikh et al. 2019). That means that algorithms trained on a specific group of patients (e.g., in a specific clinic of one city) may not be generalizable and interoperable. Therefore, when using $\mathrm{AI}$ in hospitals, generalizability should be ensured ( $\mathrm{He}$ et al. 2019; McKinney et al. 2020) to avoid unintended outcomes that could potentially harm patients' health. If an AI is too specialized on one task in one environment, it could deliver wrong treatment assistance when being transferred to another context. Generalizability could in this case be ensured if an AI would be tested in a multiple-case study.

When using $\mathrm{AI}$ in healthcare, most authors mentioned the avoidance of bias and harms as an important principle for physicians (Cath 2018; Char et al. 2018; Parikh et al. 2019; Reddy et al. 2019; Yu and Kohane 2019). Schiff and Borenstein (2016) discussed potential harms emerging from interactions between humans and AI when AI is considered as part of a medical team. They specifically discussed how responsibility should be distributed among physicians, developers, and further stakeholders, and they further provided advice for practitioners. Overall, we did not find much information or guidance on what exactly is possible harm and which precautions could be taken to avoid harm to patients. What we found was that education of an AI-literate workforce would play an important role when deploying an $\mathrm{AI}$ in a clinical environment (He et al. 2019). The introduction of an AI should therefore always involve all affected stakeholders, and all junior physicians need to be trained and educated in the areas of medical computer science and statistics (He et al. 2019). One expert explained, "I think especially young or unexperienced doctors benefit or learn from AI-based decisions. Experienced physicians have the most important parameters for the evaluation of certain disease in their heads, but this does not apply to novice physicians" (E6). In addition, the output of a predictive AI system in a health context should provide guidance for concrete medical interventions to explain the output of the prediction to physicians (Parikh et al. 2019).

One specific type of harm that was discussed in the fundamental articles was potential privacy issues (Cath 2018; Vayena et al. 2018; Zeng et al. 2019; He et al. 2019). However, we neither found detailed information on what exactly are the relevant privacy issues regarding AI use in healthcare, nor information on how possible issues could be addressed. One example could be an AI asking for sensible information that patients do not want to reveal.

When patients need to consent to the use of AI for a treatment or a therapy, they need to have trust in the system and the 
controlling physicians (Yu and Kohane 2019). Trust could be achieved through a high level of transparency and explainability. One important principle, related to transparency and explainability, is the informed consent process (Schiff and Borenstein 2016; Ting et al. 2017; Froomkin et al. 2019). To be able to agree to informed consent, the patient must understand how an $\mathrm{AI}$ is used and what consequences the use of an $\mathrm{AI}$ might have (e.g., on a treatment). Patients thus must to be made aware of the fact that some kind of AI is involved in their treatment or course of disease. One expert testified "In principle, the patient must agree to be 'treated' by an AI. This also implies explaining what this technology is doing and related consequences" (E6). This can be complicated for several reasons (Schiff and Borenstein 2016). First, the physician must have sufficient knowledge to explain the use of AI. Second, it is often difficult even for experts to understand the exact procedure of AI (black-box problem), since very large amounts of data and computing capacity are involved. One expert highlighted "We already heavily rely on certain technology. AI might yield in thinking less thus being less involved and losing the feeling of being responsible" (E2). Strategies to counteract this process could not be found in literature and need to be further investigated.

Yu and Kohane (2019) argued that the data and the algorithms need to be frequently controlled and updated to address the clinical workflow disruption. This requires not only the possibility of checking and updating, but also a continuous vigilance by the responsible physicians in hospitals (Yu et al. 2018). Not only does the system need to be checked and updated, but the feasibility of using AI in hospitals should be regularly updated as well (Gulshan et al. 2016; Yu et al. 2018; McKinney et al. 2020). It should be determined how exactly the use of AI would lead to an improvement in care (Gulshan et al. 2016). If the system is determined feasible and beneficial, the $\mathrm{AI}$ also needs to be checked for security issues to avoid cyber-attacks and errors (Zeng et al. 2019). Cyber-attacks could result in privacy violations, data misuse and even physical harm of patients through data and system manipulations.

We provide an overview of the ethical principles we extracted from the 15 fundamental manuscripts in Table 3. As not all principles were described in detail, we added some aspects of our understanding in the descriptions. Some principles were used interchangeably, which is why we provided just one description for up to three principles in some cases. We categorized the principles according to the types of issues that they may address. By regulatory issues, we refer to ethical issues that require clear rules and possible legal guidance, such as determining who is responsible for errors made by AI-assisted treatment. Normative issues are those that cannot be clearly defined by rules and laws, but should be guided by social norms (e.g., which patients should be treated first). As technical issues, we consider all types of issues that are caused by design (mostly unintentionally), such as a biased training dataset. Organizational issues are problems that could be addressed by restructuring processes within a hospital such as a lack of technical expertise of physicians, which could result in not being able to explain an AI-based treatment assistant.

In addition to the relationships between the ethical principles of AI discussed within the 15 fundamental manuscripts, we identified the citation structures between the articles. We found that the citations within our identified discourse ecosystem often differed from the citations of an article on Google Scholar or meta-databases such as Scopus meaning that the most cited manuscripts on these databased were not the ones that centrally discussed on ethical issues of using AI in hospitals. This highlights the importance of this modified discourse approach. The time span of the manuscripts we considered relevant for the ethical discourse on AI in hospitals ranged from 2016 to 2020. Most articles we identified were published in 2019. Ten of the articles formed a citation network, whereas five of the articles did not cite or were not cited by any of the other manuscripts. The most cited article within the identified network was also the most cited article on Google Scholar and Scopus on the topic of ethical frameworks of AI within healthcare. The most cited article within our identified papers was an empirical work and did not focus on theorizing on ethics and AI in hospitals (Gulshan et al. 2016). However, its findings, mentioned limitations, and conclusions were often used as a starting point for ethical discussions. In Fig. 2, we provide a timely overview of how the fundamental manuscripts cited each other and visualize ways in which future research could contribute to this network by referring to these valuable articles and connecting them to a holistic picture. For each fundamental article, we present the Google Scholar citations and the score in our network. The arrows symbolize a citation within the network and the dotted arrows offer possible points of reference for future research. Although some of the manuscripts cited each other, we found no article that discussed the others in light of ethical challenges and problems in hospitals. Rather, the articles often used different terms to describe similar aspects without referring to each other and did not specify important aspects.

\section{Discussion}

Applying the modified discourse approach proposed by Larsen et al. (2019), we identified 15 manuscripts that are fundamental for the discourse on the ethical dimensions of using AI in hospitals. Although AI and healthcare are important application fields in many disciplines, we did not find one discipline that clearly stood out. Furthermore, the identified manuscripts made little reference to each other (see Fig. 2). Although we found papers such as Gulshan et al. (2016), which were cited more frequently among the fundamental manuscripts, these were empirical papers rather than contributions to the ethical discourse in the use of AI in hospitals. However, in our identified network, we could not detect any established work reflecting 
the current discourse in academia or considering the opinions of physicians with regard to ethical considerations and dimensions of AI. With this work, we address this issue (RQ 1). In addition, we provide a research agenda in the next chapter that aims to guide academia in future works (RQ 2).

We also found that the discourse did not followed a logical structure. Five articles we considered did not refer to any other manuscripts that we classified as fundamental (Cath 2018; Vayena et al. 2018; Zeng et al. 2019; Luxton 2019; Reddy et al. 2019). This could lead to parallel discussion streams on the same topic. Interestingly, the most cited manuscript among the fundamental manuscripts was an empirical work that addressed ethical dimensions in a limited way and only within the conclusion and limitations (Gulshan et al. 2016).

Most identified articles either provided an incomplete view of the ethical challenges of applying $\mathrm{AI}$ in hospitals or functioned as empirical works that just scratched the surface of ethical principles and issues. Some of the existing articles focused on ethical challenges of very narrow AI technologies and did not consider a bigger picture (Gulshan et al. 2016; Ting et al. 2017; McKinney et al. 2020). On the other hand, some of the articles tried to derive ethical principles for the use of $\mathrm{AI}$ in healthcare which did not really differ from general ethical principles for using AI (Cath 2018; Vayena et al. 2018; Zeng et al. 2019).

Considering the fundamental manuscripts, no article focused on an overarching moral principle such as virtue ethics. Rather, the ethical perspective was not clearly defined. In the context of the ethical use of AI in hospitals, this could be deeply problematic, as virtues can be used to provide guidance to an AI-based system about what is right and wrong (Siau and Wang 2020). Future research needs to build on ethical perspectives similar to how moral virtues are discussed by Beauchamp and Childress (2019) and transfer these considerations to the context of AI applications in hospitals. Our research aims to guide this process.

Most of the principles we found were not discussed in detail and did not address the actual use of AI in hospitals (Char et al. 2018). In many articles, the same aspect was discussed using different terms such as explicability and explainability (Floridi et al. 2018; Vayena et al. 2018; Yu et al. 2018; Zeng et al. 2019) or accountability (Cath 2018; Vayena et al. 2018; Zeng et al. 2019; Reddy et al. 2019), responsibility (Cath 2018; Char et al. 2018; Zeng et al. 2019; Luxton 2019) and liability (Schiff and Borenstein 2016; Vayena et al. 2018; Yu et al. 2018; Luxton 2019; Reddy et al. 2019). In addition, ethics principles for using $\mathrm{AI}$ in healthcare are often intertwined and cannot be considered separately. However, we hardly found any discussion regarding dependencies between principles. Furthermore, detailed explanations on how ethical principles can be defined in the context of AI in hospitals were limited. Most principles lacked further definitions or were described on a meta-level that did not take into account ways in which they could be applied in healthcare. We, therefore, provide knowledge on how the principles should be examined and extended in future research. In Fig. 3, we show a structure that is more applicable for further research with dependencies of different levels of ethical principles for the use of AI in hospitals. Based on the relationships between ethical principles in the context of $\mathrm{AI}$ in hospitals, we provide a research agenda for academia.

\section{A research agenda for academia}

A philosophical perspective that specifically addresses ethical dimensions of AI in hospitals does not appear in the current discourse; although it cannot be dismissed that individual papers exist that address this topic. Researchers from various disciplines need to include this ethical perspective in their future work, as philosophical venues are classically the drivers of ethical discussions. Within the identified manuscripts, we found different categorizations of ethical principles for AI. For ethical dimensions of using $\mathrm{AI}$ in hospitals, however, we could not find a common understanding of how to structure ethical principles. Therefore, we propose a research agenda for academia whose structure is based on the widely known articles from Beauchamp and Childress (2019) on biomedical ethics and Floridi et al. (2018), who applied these principles to provide an ethical framework for a moral AI society. We argue that although the same categories of biomedical ethics are relevant for considering ethical dimensions of using AI in hospitals, their definition and compliance are not clearly actionable in further research nor in medical practice. As an overarching moral principle, we focused on a virtue ethics perspective as suggested by Siau and Wang (2020).

With our research agenda, highlighted with the results from the expert interviews, we aim to guide future research to ensure that researchers theorize and discuss the most important issues and challenges of using AI in hospitals. With their knowledge, interdisciplinary scholars will be able to provide guidance for physicians who must make the decisions about the use of AI in hospitals. On the other hand, they can also ensure that AI is used by hospitals for the benefit of patients and not in the interests of, for example, hospital profitability. Based on the suggestions of Beauchamp and Childress (Beauchamp and Childress 2019), we structured our research agenda into the categories of beneficence, non-maleficence, justice, and autonomy. Future research can address either one of these categories or one of the four issue types from Table 3 . For more applied work, we recommend addressing the issue types; for theoretical and philosophical work, we recommend addressing the categories of bioethical principles.

To provide guidance for future research, we propose the following research questions (Table 4), which are structured according to the four bioethical principles (Beauchamp and Childress 2019). 


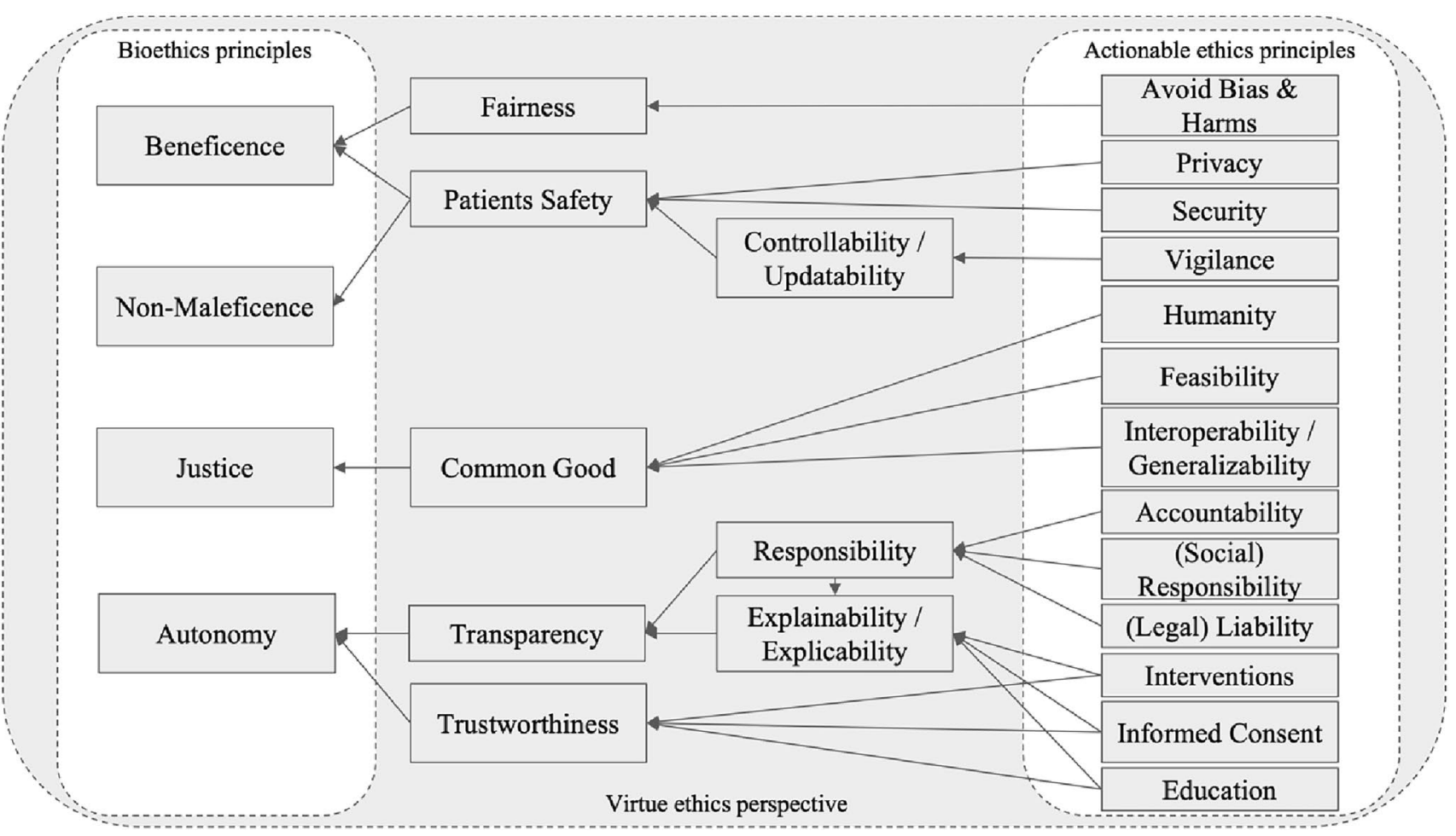

Fig. 3 Visualization of the relationship between actionable ethical principles for using AI in hospitals and bioethical principles according to Beauchamp and Childress (2019) and Floridi et al. (2018)

\subsection{Beneficence}

Floridi et al. (2018) defined beneficence as a principle that ensures that an AI promotes the well-being of humans and its output favors the common good. But what does this mean in the context of using AI in hospitals? While AI should act in a fair way (Cath 2018; Vayena et al. 2018; Zeng et al. 2019), it is not clear exactly what this implies. Further research should address in more detail the aspect of fairness in the field of AI implementation in hospitals. This would ensure the beneficence of the system in favor of the patients. Fairness can be achieved by avoiding bias and harm to all patients. For example, the use of AI should not exclude certain minority groups (e.g., people with rare diseases). One expert emphasized, "There are also ethical differences within cultures. In some countries, abortion is simply not an option for women" (E1). Previous research has highlighted cases where AI delivered poor predictions in healthcare due to biased data (Vayena et al. 2018). There are data sources that do not represent the true epidemiology within a given demographic, for example in population data biased by the entrenched overdiagnosis of schizophrenia in African Americans. In this cases AI needs mechanisms to detect incomplete or biased data. However, research on this is rare. Although some studies have detected unfair behavior of AI in hospitals, limited research has been conducted on the prevention of such issues. Using rich dataset training data for an AI could be one approach to avoid unfairness in hospitals; but how this can be achieved is a question that should be addressed. The same applies for AI violating patients' safety. Previous research has stated that patients' safety is an important factor for deciding whether an AIbased system can be used or not (Char et al. 2018; Zeng et al. 2019; He et al. 2019; Parikh et al. 2019) and discussed cases where it was violated. However, research on how to ensure patients' safety when subjected to AI treatment assistants is still rare. One expert underlined that, "AI should support with difficult therapy decisions securing the well-being of patients, for example, whether palliative or radiation treatment is more appropriate" (E3).

\subsection{Non-maleficence}

AI use in hospitals should also be non-maleficent (Floridi et al. 2018). In contrast to beneficence, which includes what an AI should do, the principle of non-maleficence aims to avoid ethical issues when using AI e.g., in hospitals. However, in previous research, we did not find a comprehensive picture of the spectrum of possible maleficence caused by AI in hospitals. Due to the black-box character of AI, it is almost impossible to predict all consequences of its use, but the current state of knowledge could be depicted. It also remains unclear how non-maleficence in hospitals can be ensured when using AI. We could derive the following aspects from 
Table 4 Formal grouping of research questions to guide future research on ethical dimensions of AI in hospitals

\begin{tabular}{|c|c|c|}
\hline Bioethical principles & Actionable principles & Exemplary research questions \\
\hline Beneficence & $\begin{array}{l}\text { Vigilance } \\
\text { Security } \\
\text { Privacy } \\
\text { Avoid bias and harms }\end{array}$ & $\begin{array}{l}\text { 1. How can the principle of fairness be defined in the context of using AI in hospitals? } \\
\text { 2. Which medical data should be used to derive AI recommendations for therapeutic and } \\
\text { treatment processes? } \\
\text { 3. How can AI systems inform decisions made by healthcare professionals? } \\
\text { 4. How can disadvantages to patients belonging to certain minority groups be removed } \\
\text { or reduced? } \\
\text { 5. In which application domains of digital health can AI be introduced as decision sup- } \\
\text { port systems to enhance hospital procedures and patient treatment? } \\
\text { 6. To what extent can AI assist with difficult therapy decisions for certain patient } \\
\text { groups? }\end{array}$ \\
\hline Non-maleficence & $\begin{array}{l}\text { Privacy } \\
\text { Security } \\
\text { Vigilance }\end{array}$ & $\begin{array}{l}\text { 1. What are possible harms caused using AI in hospitals? } \\
\text { 2. How can bias within the medical data used by AI be recognized and resolved by } \\
\text { healthcare professionals? } \\
\text { 3. How could a control mechanism for decision support for physicians through AI in } \\
\text { hospitals be designed and developed? } \\
\text { 4. How can the awareness of vigilance regarding AI used in hospitals be increased? } \\
\text { 5. How can it be ensured that medical information is not retrieved by third parties? } \\
6 \text {. To what extent can external data manipulations within AI datasets be detected and } \\
\text { prevented by physicians? }\end{array}$ \\
\hline Justice & $\begin{array}{l}\text { Humanity } \\
\text { Feasibility } \\
\text { Interoperability/generalizability }\end{array}$ & $\begin{array}{l}\text { 1. How can AI applications in hospitals contribute to the common good of a society? } \\
\text { 2. How can common good be defined and interpreted by AI applied in clinical environ- } \\
\text { ments? } \\
\text { 3. Which guidelines are essential to ensure common good when using AI in hospitals? } \\
\text { 4. To what extent can physicians be psychologically relieved of moral dilemmas when } \\
\text { using AI in hospitals? } \\
\text { 5. How is AI able to improve the doctor-patient relationship in hospitals? } \\
\text { 6. How can existing AI applications in hospitals be transferred to other conditions, } \\
\text { departments, countries, and cultures? } \\
\text { 7. To what extent are generalizable AI results ensured? }\end{array}$ \\
\hline Autonomy & $\begin{array}{l}\text { Accountability } \\
\text { (Social) Responsibility } \\
\text { (Legal) Liability } \\
\text { Interventions } \\
\text { Informed consent } \\
\text { Education }\end{array}$ & $\begin{array}{l}\text { 1. To what extent do physicians perceive themselves to be losing their autonomy when } \\
\text { AI is applied in hospitals? } \\
\text { 2. How should the application of AI in hospitals be transparently presented to medical } \\
\text { experts and patients? } \\
\text { 3. Who can be held accountable and socially responsible for AI-driven decisions, and } \\
\text { under which clinical conditions? } \\
\text { 4. How can the legal liability for using AI in hospitals be clarified and implemented in a } \\
\text { legal foundation? } \\
\text { 5. Who is accountable and responsible for ensuring legal alignment when using AI in } \\
\text { hospitals? } \\
\text { 6. How can AI accompany its outputs with concrete recommendations for use in medical } \\
\text { interventions? } \\
\text { 7. How can it be ensured that both the physicians and the patients are aware of the con- } \\
\text { sequences when consenting to the use of AI in a hospital? } \\
\text { 8. How should AI applications be designed to be utilized only under voluntary condi- } \\
\text { tions among clinicians and patients? } \\
\text { 9. How do we need to educate and train physicians to ensure an ethical use of AI in } \\
\text { hospitals? } \\
\text { 10. What kind of training increases trustworthiness in using AI in hospitals? }\end{array}$ \\
\hline
\end{tabular}

the literature that refer to non-maleficence: patients' safety, privacy, security, controllability, updatability, and vigilance (Cath 2018; Char et al. 2018; Vayena et al. 2018; Yu et al. 2018; Zeng et al. 2019; He et al. 2019; Parikh et al. 2019; Yu and Kohane 2019; McKinney et al. 2020).

When applying AI in a hospital, possible violations of patients' privacy must be identified and solutions need to be developed. However, AI could also cause physical damage to patients' health, for example, when delivering decision support for diagnoses or medications. Although the highlighted training dataset is also potentially relevant for this, future research needs to determine which decisions could be supported by AI and how this decision support could be controlled. However, it seems that the decision support, e.g., regarding treatment recommendations, should always be monitored and assessed by human physicians: "It will never be the case that an AI takes over the complete diagnosis. It will always be the case that there is a choice and the human 
being decides at the end of the day" (E6). The technical controllability and updatability of a system, as well as the vigilance of the physicians, need to be ensured. In addition to monitoring AI for internal errors, we identified ethical issues regarding the external security of a system. For example, cyber-attacks could manipulate the data basis of an AI without the users noticing. Therefore, future research needs to address these types of security issues when using $\mathrm{AI}$ in hospitals. This leads us to the following further research questions: How can awareness for vigilance be increased?

\subsection{Justice}

The principle of justice covers aspects that "contribute to global justice and equal access to the benefits" for individuals and society (Floridi et al. 2018). In the literature, we found overlaps with the principle of fairness that aimed at avoiding any type of discrimination (Cath 2018; Vayena et al. 2018; Zeng et al. 2019). For a sharper demarcation, however, in this article, we focus on the aspect of common good when mentioning fairness. Future research should investigate what common good exactly implies and how common good can be achieved by AI. This might contain "psychological relief from doctors in the context of a triage" (E2), i.e., classification of patients in a crisis according to the severity of the injuries, but also "improving the doctor-patient relationship when AI handles standard procedures" (E4). In the literature of fundamental manuscripts on the ethical dimensions of AI in hospitals, we found four actionable principles that can be assigned to common good and justice: humanity, feasibility, interoperability, and generalizability (Gulshan et al. 2016; Char et al. 2018; Yu et al. 2018; Zeng et al. 2019; He et al. 2019; Parikh et al. 2019; McKinney et al. 2020). Future research should investigate which AI applications in hospitals can benefit humanity. Furthermore, for each AI application, the technical feasibility of the application for the common good needs to be evaluated. In many cases, AI technologies in hospitals are only used for a very specific case within a system, e.g., in angiography: "There are AI-based systems, for example in angiography, which determine with a certain probability and based on certain points that are detected within a vessel, what the rest of the vessel might look like" (E6). Future research should focus on how to make these AI systems interoperable and how to make the outputs of an AI-based system in hospitals more generalizable.

\subsection{Autonomy}

As another principle of bioethics, autonomy is defined as the right of patients to make decisions about their treatments, which implies that they mentally understand the situation (Beauchamp and Childress 2019). With AI, the question arises how patients' autonomy can be ensured as we willingly "cede some of our decision-making power to machines" (Floridi et al. 2018, p. 698). Future research should focus on how autonomy has to be ensured when using AI as support for a treatment and how this autonomy can be achieved. One expert explained, "the patient is in the center of attention" (E1) and further "as a physician you cannot evade responsibility" (E4).

In the literature, we found two fundamental principles by which autonomy can be achieved: transparency (Cath 2018; Vayena et al. 2018; Zeng et al. 2019; Froomkin et al. 2019; He et al. 2019) and trustworthiness (Yu and Kohane 2019). If patients have transparency about the use and application of $\mathrm{AI}$ in a hospital on the one hand, and trust in the way it works on the other hand, autonomy can be achieved. One way of achieving trust is to "show the power behind it. If you do studies like the one with Watson and show comparatively that an $\mathrm{AI}$ achieves several times better results than a human expert, then that naturally creates trust" (E6). According to E6, presenting the advantages of accompanied studies could be an adequate strategy to increase trustworthiness. However, to ensure adherence to both principles, more detailed aspects must be considered. Transparency does not only imply that a patient is informed about whether $\mathrm{AI}$ is being used and could potentially understand how it works. Transparency also includes explaining to the patient exactly how an AI-based system works and how its use might affect his or her treatment (Vayena et al. 2018; Yu et al. 2018; Zeng et al. 2019). This requires considering not only the principle of explicability, but also the principle of responsibility. The patients must be aware of who is responsible for the consequences and outputs of the use of AI in a hospital. We found three types of responsibility that future research should examine more closely: functional accountability (Cath 2018; Vayena et al. 2018; Zeng et al. 2019; Reddy et al. 2019), social responsibility (Cath 2018; Char et al. 2018; Zeng et al. 2019; Luxton 2019), and legal liability (Schiff and Borenstein 2016; Vayena et al. 2018; Yu et al. 2018; Luxton 2019; Reddy et al. 2019). This is also in accordance with E6, who stated, "The question of responsibility has not yet been conclusively clarified and is, therefore, philosophical to a certain degree. We as company are accountable for keeping our stable clean. But we should also have the doctors who can also question this again in case of doubt. But a certain amount of legal liability should also lie with the manufacturer, who should also be responsible for ensuring that the $\mathrm{AI}$ is always up to date."

Future research should, therefore, look at who is operationally responsible for $\mathrm{AI}$ and who has the authority to issue instructions on the use of AI, as well as who may not be directly responsible for the consequences of the use of AI but should be involved from an ethical perspective. In addition, it should be further investigated how the legal framework for the use of AI in hospitals should be designed and how it can be ensured that both physicians and patients are aware of it. A precise explanation of responsibility is part of the explainability of the ethical framework. How exactly this explainability can be ensured has not yet been sufficiently researched. We 
found three actionable principles that could enable explainability of AI: interventions (Parikh et al. 2019), informed consent (Schiff and Borenstein 2016; Ting et al. 2017; Froomkin et al. 2019), and education (He et al. 2019). Future research should address the fact that the use of AI should always be accompanied by concrete recommendations for interventions by physicians, as they must interpret the AI's outputs. Further research is also needed to determine exactly how these interventions should be designed. Another sub-area of ethical research in $\mathrm{AI}$ is informed consent. Future research should explore ways to ensure that physicians explain the effects of the use of AI to patients well enough to enable confident decisions on whether to consent or refuse. However, to ensure explicability, physicians need to be trained in this matter. Future research should explore in more detail what types of training and education are needed to enable the explainability of AI to the patient. Interventions, informed consent, and education are also important components in creating trustworthiness. Future research should explore how exactly trust can be created in a system on the part of physicians and patients. However, trust in AI must be treated with caution, as clinicians "rely on the technology and become dependent on it" and further, "AI does the thinking and people act blindly" (E2).

\section{Conclusion and limitations}

In this article, we presented the current discourse in the domain ecosystem of ethical considerations on $\mathrm{AI}$ in hospitals. Drawing from theoretical foundations (i.e., Beauchamp and Childress 2019; Floridi et al. 2018), enlightened by semi-structured expert interviews with clinicians, this article contributes to theoretical foundations by presenting research areas that need to be faced when AI is used in hospitals. These results are highly relevant for practitioners, academia, and healthcare researchers and inform societal issues and challenges.

The main theoretical contribution of this research is the proposal of a research agenda explaining where in-depth investigations are needed. Our study demonstrates that current research scratches the surface rather than conducting profound examinations. We thus guide scholars' efforts for future studies and encourage the prospective discourse of ethical considerations of AI in healthcare. On a practical level, physicians comprehend to what extent the application of $\mathrm{AI}$ in hospitals seems fruitful as well as where ethical questions arise that could affect patients' physical and psychological well-being. We, therefore, aim to raise practitioners' awareness for the possible up- and the downsides of AI in healthcare. In terms of implications for society, individuals realize that ethical considerations of AI are vital, as the overall well-being of patients has the highest priority among clinicians.
As with all research, certain limitations apply. Since we aimed to identify highly relevant and fundamental theory-building papers (L1), we did not take a closer look at other papers citing these publications (L2, L3). In total, we have identified 15 fundamental articles, providing a sufficient foundation for our research agenda. However, it is possible that we could have missed some relevant literature investigating ethical considerations and dimensions of $\mathrm{AI}$ in hospitals, which may have provided additional knowledge. Moreover, we retrieved articles from interdisciplinary outlets and conducted a forward as well as backward search to obtain relevant publications from related disciplines. Even though the fundamental theory-building papers are from various disciplines and thus provide transferable results, publications from other sources (i.e., PubMed, an essential database for biomedical literature) might have yielded additional insights. Furthermore, the group of experts we interviewed was quite homogenous, with a small number of individuals that only cover a limited fraction of knowledge. Interviewing additional hospital employees, i.e., clinicians from other departments or employees working in other hierarchies as nursing staff, might have led to a more holistic picture.

We invite scholars to address the exemplary research questions we have provided in this article in the context of the bioethical principles. The citation network of the 15 fundamental manuscripts can be used as a starting point to better highlight the ethical discourse of AI in hospitals and to extend and deepen our discussion. We suggest that researchers consider virtue ethics as the main ethical perspective, as virtues need to be defined when AI-based systems are applied for treatment support in hospitals. The 18 ethical principles we found, and especially the 13 actionable principles, contribute to the discourse of AI use in hospitals and can serve as guidance for academia as well as physicians and healthcare decision-makers.

\section{Appendix}

See Tables 5 and 6.
Table 5 Ranking of identified articles according to their number of citations

\begin{tabular}{ll}
\hline Number of citations & $\begin{array}{l}\text { Num- } \\
\text { ber of } \\
\text { papers }\end{array}$ \\
\hline 8 & 2 \\
6 & 2 \\
5 & 2 \\
4 & 7 \\
3 & 23 \\
2 & 115 \\
1 & 2713 \\
\hline
\end{tabular}


Table 6 Interview guideline (German interview questions have been translated into English)

\begin{tabular}{ll}
\hline Phase & Research goal \\
\hline Briefing & Welcoming the interviewee and providing \\
& general information about the research and \\
& brief introduction to the topic
\end{tabular}

Demographic data

Ethical considerations in healthcare and hospitals

Ethical considerations and technology

Ethical considerations and AI

$\mathrm{AI}$ and future perspectives

Debriefing

Supplementary Information The online version contains supplementary material available at https://doi.org/10.1007/s00146-021-01239-4.

Funding Open Access funding enabled and organized by Projekt DEAL.
Ethical considerations physicians are confronted with and whether they follow a certain codex

Ethical problems technology raises and how they are capable to resolve ethical issues

Specific questions on the application of $\mathrm{AI}$ in hospitals and which factors are crucial for a deployment and what ethical guidelines must be follow
Questions

a. Could you please introduce yourself?

b. What is your current position in the hospital?

c. What responsibilities does your position involve?

d. How long have you been working in this position / in this hospital?

a. What ethical considerations are you confronted with in your everyday work?

b. What is the ethical code you follow?

a. Which technologies are used in your hospital to support your work?

b. Which technologies do you rely on for your decisions?

c. Which ethical problems can technology cause? What questions arise?

d. Which ethical problems can a technology help to solve?

a. What do you associate with the term "artificial intelligence"?

Providing an explanation of AI and current examples to assume the same knowledge among all participants

b. For which tasks can AI be used as support in hospitals?

c. Which tasks can AI be allowed to take over independently and which not?

d. Which factors must AI consider when being used hospitals? Which rules must be obeyed?

e. What is AI not allowed to decide for itself? What outcomes need to be prevented? What negative consequences may result?

f. What are ethical conditions, requirements, and challenges for the application of $\mathrm{AI}$ in hospitals?

g. Which morally reprehensible decisions should AI not derive?

h. Which moral decisions could an AI make better compared to a human being?

a. For what purposes would you use like to use AI in hospitals?

b. Which decision would you rather follow, that of a human or an AI? Please elaborate

c. How do you think is the role of AI in hospitals changing in the future?

Debriefing of the interviewee and explanation of the research background, possibility for the interviewee to ask further question or giving closing remarks a. What other question did you expect but was not asked?

b. Do you have further questions / comments on the topic? 
were made. The images or other third party material in this article are included in the article's Creative Commons licence, unless indicated otherwise in a credit line to the material. If material is not included in the article's Creative Commons licence and your intended use is not permitted by statutory regulation or exceeds the permitted use, you will need to obtain permission directly from the copyright holder. To view a copy of this licence, visit http://creativecommons.org/licenses/by/4.0/.

\section{References}

AEM (2020) Akademie für Ethik in der Medizin-Ziele und Aufgaben. https://www.aem-online.de/. Accessed 29 Apr 2021

Alami H, Lehoux P, Auclair Y et al (2020) Artificial intelligence and health technology assessment: anticipating a new level of complexity. J Med Internet Res 22:e17707. https://doi.org/10.2196/17707

AMA (2020) American Medical Association Principles of Medical Ethics. https://www.ama-assn.org/delivering-care/ethics/code-medical-ethics-overview. Accessed 29 Apr 2021

Amnesty International (2020) Help women and girls in Poland fight dangerous new restrictions on abortion. https://www.amnesty. org/en/get-involved/take-action/help-women-and-girls-in-polandfight-new-restrictions-on-abortion/. Accessed 15 Apr 2021

Anderson M, Anderson SL (2007) Machine ethics: creating an ethical intelligent agent. AI Mag 28:15-26

Arnold T, Scheutz M (2018) The "big red button" is too late: an alternative model for the ethical evaluation of AI systems. Ethics Inf Technol 20:59-69. https://doi.org/10.1007/s10676-018-9447-7

Atherton PJ, Smith T, Singh JA et al (2013) The relation between cancer patient treatment decision-making roles and quality of life. Cancer 119:2342-2349. https://doi.org/10.1002/cncr.28046

Bærøe K, Miyata-Sturm A, Henden E (2020) How to achieve trustworthy artificial intelligence for health. Bull World Health Organ 98:257-262. https://doi.org/10.2471/BLT.19.237289

Bargshady G, Zhou X, Deo RC et al (2020) Enhanced deep learning algorithm development to detect pain intensity from facial expression images. Expert Syst Appl 149:113305. https://doi. org/10.1016/j.eswa.2020.113305

Barredo Arrieta A, Díaz-Rodríguez N, Del Ser J et al (2020) Explainable Artificial Intelligence (XAI): concepts, taxonomies, opportunities and challenges toward responsible AI. Inf Fusion 58:82-115. https://doi.org/10.1016/j.inffus.2019.12.012

Batin M, Turchin A, Markov S et al (2017) Artificial intelligence in life extension: from deep learning to superintelligence. Informatica 41:401-417

Bear A, Knobe J (2016) Normality: part descriptive, part prescriptive. Cognition 167:25-37. https://doi.org/10.1016/j.cognition. 2016.10.024

Beauchamp TL, Childress JF (2019) Principles of biomedical ethics, 8th edn. Oxford University Press, New York

Bell DE (1989) Decision making: descriptive, normative, and prescriptive interactions. Cambridge University Press

Bickmore T, Puskar K, Schlenk E et al (2010) Maintaining reality: relational agents for antipsychotic medication adherence. Interact Comput 22:276-288. https://doi.org/10.1016/j.intcom.2010.02.001

Boell SK, Blair W (2019) An IT artifact supporting exploratory literature searches. In: Australasian conference on information systems. http://www.litbaskets.io. Accessed 21 Jun 2021

Bore M, Munro D, Kerridge I, Powis D (2005) Selection of medical students according to their moral orientation. Med Educ 39:266-275. https://doi.org/10.1111/j.1365-2929.2005.02088.x

Brachten F, Brünker F, Frick NRJ et al (2020) On the ability of virtual agents to decrease cognitive load: an experimental study. Inf Syst E-Bus Manag 18:187-207. https://doi.org/10.1007/ s10257-020-00471-7
Brendel AB, Mirbabaie M, Lembcke TB, Hofeditz L (2021) Ethical management of artificial intelligence. Sustainability 13:1-18. https://doi.org/10.3390/su13041974

Burton RJ, Albur M, Eberl M, Cuff SM (2019) Using artificial intelligence to reduce diagnostic workload without compromising detection of urinary tract infections. BMC Med Inform Decis Mak 19:1-11. https://doi.org/10.1186/s12911-019-0878-9

Bygstad B, Øvrelid E, Lie T, Bergquist M (2020) Developing and organizing an analytics capability for patient flow in a general hospital. Inf Syst Front 22:353-364. https://doi.org/10.1007/ s10796-019-09920-2

Cath C (2018) Governing artificial intelligence: ethical, legal and technical opportunities and challenges. Philos Trans R Soc A Math Phys Eng Sci. https://doi.org/10.1098/rsta.2018.0080

CEOM (2020) Principles of European Medical Ethics. http://www. ceom-ecmo.eu/en/view/principles-of-european-medical-ethics. Accessed 29 Apr 2021

Char DS, Shah NH, Magnus D (2018) Implementing machine learning in health care-addressing ethical challenges. N Engl J Med 378:979-981

Crawford K, Calo R (2016) There is a blind spot in AI research. Nature 538:311-313

Creswell JW, Creswell DJ (2018) Research design: qualitative, quantitative, and mixed methods. SAGE Publications

De Ramón Fernández FA, Ruiz Fernández D, Prieto Sánchez MT (2019) A decision support system for predicting the treatment of ectopic pregnancies. Int J Med Inform 129:198-204. https:// doi.org/10.1016/j.ijmedinf.2019.06.002

Denecke K, Lutz Hochreutener S, Pöpel A, May R (2018) Talking to ana: a mobile self-anamnesis application with conversational user interface. In: International Conference on Digital Health. ACM: New York, US

Devi D, Biswas SK, Purkayastha B (2019) Learning in presence of class imbalance and class overlapping by using one-class SVM and undersampling technique. Conn Sci 31:105-142. https://doi. org/10.1080/09540091.2018.1560394

Diederich S, Brendel AB, Kolbe LM (2019) On conversational agents in information systems research: analyzing the past to guide future work. In: Proceedings of 14th International Conference on Wirtschaftsinformatik. AISel: Siegen, Germany

Dilsizian SE, Siegel EL (2014) Artificial intelligence in medicine and cardiac imaging: harnessing big data and advanced computing to provide personalized medical diagnosis and treatment. Curr Cardiol Rep 16:441. https://doi.org/10.1007/s11886-013-0441-8

Duan Y, Edwards JS, Dwivedi YK (2019) Artificial intelligence for decision making in the era of big data-evolution, challenges and research agenda. Int J Inf Manag 48:63-71. https://doi.org/ 10.1016/j.ijinfomgt.2019.01.021

EU (2020) Ethics guidelines for trustworthy AI. https://ec.europa.eu/ futurium/en/ai-alliance-consultation. Accessed 29 Apr 2021

Floridi L, Cowls J, Beltrametti M et al (2018) AI4 people-an ethical framework for a good AI society: opportunities, risks, principles, and recommendations. Minds Mach 28:689-707. https://doi.org/ $10.1007 / \mathrm{s} 11023-018-9482-5$

Fox G, James TL (2020) Toward an understanding of the antecedents to health information privacy concern: a mixed methods study. Inf Syst Front. https://doi.org/10.1007/s10796-020-10053-0

Frick N, Brünker F, Ross B, Stieglitz S (2019a) The utilization of artificial intelligence for improving incident management. HMD 56:357-369. https://doi.org/10.1365/s40702-019-00505-w

Frick NRJ, Brünker F, Ross B, Stieglitz S (2019b) Towards Successful Collaboration: Design Guidelines for AI-based Services enriching Information Systems in Organisations. In: Proceedings of the 30th Australasian Conference on Information Systems. ArXiv, Fremantle, Australia, p arXiv:1912.01077 
Froomkin AM, Kerr I, Pineau J (2019) Confronting the challenges of the world. Call Holin 61:167-170. https://doi.org/10.2307/j. ctt1p6qpn7.29

Gioia DA, Corley KG, Hamilton AL (2013) Seeking qualitative rigor in inductive research. Organ Res Methods 16:15-31. https://doi. org/10.1177/1094428112452151

Glaser BG (2013) No preconceptions: the grounded theory dictum. Sociology Press, Mill Valley

Gnewuch U, Morana S, Adam M, Maedche A (2017) Towards Designing Cooperative and Social Conversational Agents for Customer Service. In: Proceedings of the Thirty Eighth International Conference on Information Systems. CCBY-NC-ND 4.0 license http://creativecommons.org/licenses/bync-nd/4.0/. South Korea

Gruson D, Helleputte T, Rousseau P, Gruson D (2019) Data science, artificial intelligence, and machine learning: opportunities for laboratory medicine and the value of positive regulation. Clin Biochem 69:1-7. https://doi.org/10.1016/j.clinbiochem.2019. 04.013

Gulshan V, Peng L, Coram M et al (2016) Development and validation of a deep learning algorithm for detection of diabetic retinopathy in retinal fundus photographs. J Am Med Assoc 316:2402-2410. https://doi.org/10.1001/jama.2016.17216

He J, Baxter SL, Xu J et al (2019) The practical implementation of artificial intelligence technologies in medicine. Nat Med 25:30-36. https://doi.org/10.1038/s41591-018-0307-0

Hebert PC, Meslin EM, Dunn EV (1992) Measuring the ethical sensitivity of medical students: a study at the University of Toronto. J Med Ethics 18:142-147. https://doi.org/10.1136/jme.18.3.142

Hirschauer TJ, Adeli H, Buford JA (2015) Computer-aided diagnosis of Parkinson's disease using enhanced probabilistic neural network. J Med Syst. https://doi.org/10.1007/s10916-015-0353-9

Hulkower R (2010) The history of the hippocratic oath: outdated, inauthentic, and yet still relevant 4 commentary. Einstein J Biol Med 25:41-44

Jain AK, Mao J, Mohiuddin KM (1996) Artificial neural networks: a tutorial. Computer (long Beach Calif) 29:31-44. https://doi.org/ $10.1109 / 2.485891$

Jiang F, Jiang Y, Zhi H, et al (2017) Artificial intelligence in healthcare: past, present and future. Stroke Vasc Neurol 0:e000101. https:// doi.org/10.1136/svn-2017-000101

Kara S, Güven A, Okandan M, Dirgenali F (2006) Utilization of artificial neural networks and autoregressive modeling in diagnosing mitral valve stenosis. Comput Biol Med 36:473-483. https://doi. org/10.1016/j.compbiomed.2005.01.007

Ker J-I, Wang Y, Hajli N (2018) Examining the impact of health information systems on healthcare service improvement: The case of reducing in patient-flow delays in a U.S. hospital. Technol Forecast Soc Change 127:188-198. https://doi.org/10.1016/j. techfore.2017.07.013

Kimani E, Bickmore T, Trinh H, et al (2016) A Smartphone-Based Virtual Agent for Atrial Fibrillation Education and Counseling. In: Lecture Notes in Computer Science: Proceedings of the International Conference on Intelligent Virtual Agents, 10011th edn. Springer: Los Angeles, US. pp 120-127

King A, Bickmore T, Campero M et al (2013) Employing virtual advisors in preventive care for underserved communities: results from the COMPASS study. J Health Commun 18:1449-1464. https:// doi.org/10.1080/10810730.2013.798374

Knight W (2017) The dark secret at the heart of AI. MIT Technol Rev. https://www.technologyreview.com/2017/04/11/5113/the-darksecret-at-the-heart-of-ai/. Accessed 21 Jun

Knijnenburg B, Willemsen M (2016) Inferring capabilities of intelligent agents from their external traits. ACM Trans Interact Intell Syst 6:1-25. https://doi.org/10.1145/2963106
Krittanawong C, Zhang H, Wang Z et al (2017) Artificial intelligence in precision cardiovascular medicine. J Am Coll Cardiol 69:26572664. https://doi.org/10.1016/j.jacc.2017.03.571

$\mathrm{Ku} \mathrm{CH}$, Chang Y-C, Wang Y, et al (2019) Artificial Intelligence and Visual Analytics: A Deep-Learning Approach to Analyze Hotel Reviews \& Responses. In: Proceedings of the 52nd Hawaii International Conference on System Sciences. HICSS: CC BY-NCND 4.0, Hawaii, pp 5268-5277

Larsen KR, Hovorka DS, Dennis AR, West JD (2019) Understanding the elephant: the discourse approach to boundary identification and corpus construction for theory review articles. J Assoc Inf Syst 20:887-927. https://doi.org/10.17705/1jais.00556

Li H, Wang X, Liu C et al (2019a) Dual-input neural network integrating feature extraction and deep learning for coronary artery disease detection using electrocardiogram and phonocardiogram. IEEE Access 7:146457-146469. https://doi.org/10.1109/ ACCESS.2019.2943197

Li Y, Deng X, Wang Y (2019b) Introduction to the minitrack on augmenting human intelligence: artificially, socially, and ethically. In: Proceedings of the 52nd Hawaii International Conference on System Sciences, Manoa, Hawaii, pp 5266-5267

Libaque-Sáenz CF, Wong SF, Chang Y, Bravo ER (2020) The effect of fair information practices and data collection methods on privacy-related behaviors: a study of mobile apps. Inf Manag. https://doi.org/10.1016/j.im.2020.103284

López-Martínez F, Núñez-Valdez ER, Lorduy Gomez J, García-Díaz V (2019) A neural network approach to predict early neonatal sepsis. Comput Electr Eng 76:379-388. https://doi.org/10.1016/j. compeleceng.2019.04.015

Luger E, Sellen A (2016) "Like Having a Really Bad PA": the gulf between user expectation and experience of conversational agents. In: Proceedings of the $2016 \mathrm{CHI}$ Conference on Human Factors in Computing Systems. ACM: New York, US, pp 5286-5297

Luxton DD (2014a) Recommendations for the ethical use and design of artificial intelligent care providers. Artif Intell Med. https:// doi.org/10.1016/j.artmed.2014.06.004

Luxton DD (2014b) Artificial intelligence in psychological practice: current and future applications and implications. Prof Psychol Res Pract 45:332-339. https://doi.org/10.1037/a0034559

Luxton DD (2019) Should watson be consulted for a second opinion? AMA J Ethics 21:131-137. https://doi.org/10.1001/amajethics. 2019.131

McKinney SM, Sieniek M, Godbole V et al (2020) International evaluation of an AI system for breast cancer screening. Nature 577:8994. https://doi.org/10.1038/s41586-019-1799-6

Menai MEB (2015) Random forests for automatic differential diagnosis of erythemato-squamous diseases. Int J Med Eng Inform 7:124-141. https://doi.org/10.1504/IJMEI.2015.068506

Menschner P, Prinz A, Koene P et al (2011) Reaching into patients' homes-participatory designed AAL services: the case of a patient-centered nutrition tracking service. Electron Mark 21:6376. https://doi.org/10.1007/s12525-011-0050-6

Meuser M, Nagel U (2009) The expert interview and changes in knowledge production. In: AB et al. (eds) Interviewing experts. Palgrave Macmillan, London, pp 17-42

Miles SH (2005) The hippocratic oath and the ethics of medicine. Oxford University Press, New York

Mirbabaie M, Stieglitz S, Brünker F et al (2020) Understanding collaboration with virtual assistants-the role of social identity and the extended self. Bus Inf Syst Eng. https://doi.org/10.1007/ s12599-020-00672-x

Mirbabaie M, Stieglitz S, Frick NRJ (2021a) Hybrid intelligence in hospitals: towards a research agenda for collaboration. Electron Mark. https://doi.org/10.1007/s12525-021-00457-4 
Mirbabaie M, Stieglitz S, Frick NRJ (2021b) Artificial intelligence in disease diagnostics : a critical review and classification on the current state of research guiding future direction. Health Technol (berl). https://doi.org/10.1007/s12553-021-00555-5

Mitchell T, Cohen W, Hruschka E et al (2018) Never-ending learning. Commun ACM 61:103-115. https://doi.org/10.1145/3191513

Nalini S (2019) Determination of muscles of head acting in whistling. Int J Physiol 7:1. https://doi.org/10.5958/2320-608x.2019. 00033.7

Nasirian F, Ahmadian M, Lee O-K (Daniel) (2017) AI-based voice assistant systems: evaluating from the interaction and trust perspectives. In: Proceedings of the Twenty-third American Conference on Information Systems. AISel, Boston, US

Neill DB (2013) Using artificial intelligence to improve hospital inpatient care. IEEE Intell Syst 28:92-95. https://doi.org/10.1109/ MIS.2013.51

Page K (2012) The four principles: can they be measured and do they predict ethical decision making? BMC Med Ethics. https://doi. org/10.1186/1472-6939-13-10

Parikh RB, Obermeyer Z, Navathe AS (2019) Regulation of predictive analytics in medicine. Algorithms must meet regulatory standards of clinical benefit. Science 363:6429. https://doi.org/ 10.1126/science.aaw0029

Pereira C, McNamara A, Sorge L, Arya V (2013) Personalizing public health: your health avatar. J Am Pharm Assoc 53:145-151. https://doi.org/10.1331/JAPhA.2013.12207

Ploug T, Holm S (2020) The right to refuse diagnostics and treatment planning by artificial intelligence. Med Health Care Philos 23:107-114. https://doi.org/10.1007/s11019-019-09912-8

Porra J, Lacity M, Parks MS (2020) "Can computer based humanlikeness endanger humanness?"- a philosophical and ethical perspective on digital assistants expressing feelings they can't have. Inf Syst Front 22:533-547. https://doi.org/10.1007/ s10796-019-09969-z

Preece A, Webberley W, Braines D et al (2017) Sherlock: experimental evaluation of a conversational agent for mobile information tasks. IEEE Trans Hum Mach Syst 47:1017-1028. https://doi.org/10. 1109/THMS.2017.2700625

Price J, Price D, Williams G, Hoffenberg R (1998) Changes in medical student attitudes as they progress through a medical course. J Med Ethics 24:110-117. https://doi.org/10.1136/jme.24.2.110

Qu S, Dumay J (2011) The qualitative research interview. Qual Res Account Manag 8:238-264. https://doi.org/10.1108/1176609111 1162070

Rai A, Constantinides P, Sarker S (2019) Next-generation digital platforms: toward human-AI hybrids. MIS Q 43:iii-ix

Rauschert S, Raubenheimer K, Melton PE, Huang RC (2020) Machine learning and clinical epigenetics: a review of challenges for diagnosis and classification. Clin Epigenet. https://doi.org/10.1186/ s13148-020-00842-4

Reddy S, Fox J, Purohit MP (2019) Artificial intelligence-enabled healthcare delivery. J R Soc Med 112:22-28. https://doi.org/10. $1177 / 0141076818815510$

Rezler AG, Lambert P, Obenshain SS et al (1990) Professional decisions and ethical values in medical and law students. Acad Med 65:31-32

Rezler AG, Schwartz RL, Obenshain SS et al (1992) Assessment of ethical decisions and values. Med Educ 26:7-16. https://doi. org/10.1111/j.1365-2923.1992.tb00115.x

Riddick FA (2003) The code of medical ethics of the American Medical Association. https://www.ama-assn.org/deliveringcare/ethics/code-medical-ethics-overview. Accessed 21 Jun

Rong G, Mendez A, Bou Assi E et al (2020) Artificial intelligence in healthcare: review and prediction case studies. Engineering 6:291-301. https://doi.org/10.1016/j.eng.2019.08.015
Rosen MA, DiazGranados D, Dietz AS et al (2018) Teamwork in healthcare: key discoveries enabling safer, high-quality care. Am Psychol 73:433-450. https://doi.org/10.1037/amp0000298

Rudin C (2019) Stop explaining black box machine learning models for high stakes decisions and use interpretable models instead. Nat Mach Intell 1:206-215. https://doi.org/10.1038/ s42256-019-0048-x

Salerno J, Knoppers BM, Lee LM et al (2017) Ethics, big data and computing in epidemiology and public health. Ann Epidemiol 27:297-301. https://doi.org/10.1016/j.annepidem.2017.05.002

Schiff D, Borenstein J (2016) AMA Journal of Ethics®. Clin Ethics $18: 473-563$

Schilling J (2006) On the pragmatics of qualitative assessment. Eur J Psychol Assess 22:28-37. https://doi.org/10.1027/1015-5759. 22.1.28

Seeber I, Bittner E, Briggs RO et al (2020) Machines as teammates: a research agenda on $\mathrm{AI}$ in team collaboration. Inf Manag 57:103174. https://doi.org/10.1016/j.im.2019.103174

Serrano A, Garcia-Guzman J, Xydopoulos G, Tarhini A (2020) Analysis of barriers to the deployment of health information systems: a stakeholder perspective. Inf Syst Front 22:455-474. https://doi.org/10.1007/s10796-018-9869-0

Shaked N (2017) Avatars and virtual agents-relationship interfaces for the elderly. Healthc Technol Lett 4:83-87. https://doi.org/ 10.1049/htl.2017.0009

Siau K, Wang W (2018) Building trust in artificial intelligence, machine learning, and robotics. Cut Bus Technol J 31:47-53

Siau K, Wang W (2020) Artificial intelligence (AI) ethics. J Database Manag 31:74-87. https://doi.org/10.4018/jdm.2020040105

Sonja M, Ioana G, Miaoqing Y, Anna K (2018) Understanding value in health data ecosystems: a review of current evidence and ways forward. Rand Health Q 7(2):3, PMID: 29416943; PMCID: PMC5798965

Ting DSW, Cheung CYL, Lim G et al (2017) Development and validation of a deep learning system for diabetic retinopathy and related eye diseases using retinal images from multiethnic populations with diabetes. J Am Med Assoc 318:2211-2223. https://doi.org/10.1001/jama.2017.18152

Vayena E, Blasimme A, Cohen IG (2018) Machine learning in medicine: addressing ethical challenges. PLoS Med 15:4-7. https:// doi.org/10.1371/journal.pmed.1002689

vom Brocke J, Simons A, Niehaves et al (2009) Reconstructing the giant: on the importance of rigour in documenting the literature search process. In: Proceedings of the 17th European Conference on Information Systems, AISel, Verona, Italy

vom Brocke J, Simons A, Riemer K et al (2015) Standing on the shoulders of giants: challenges and recommendations of literature search in information systems research. Commun Assoc Inf Syst. https://doi.org/10.17705/1CAIS.03709

Walker S (2020) Poland delays abortion ban as nationwide protests continue. https://www.theguardian.com/world/2020/ nov/03/poland-stalls-abortion-ban-amid-nationwide-protests. Accessed 21 Jun

Wang Y (2020) Toward an understanding of responsible artificial intelligence practices. In: Proceedings of the 53rd Hawaii International Conference on System Sciences, HICSS CC BYNC-ND 4.0, Hawaii, pp 4962-4971

Wears RL, Berg M (2005) Computer technology and clinical work. J Am Med Assoc 293:1261-1263. https://doi.org/10.1001/jama. 293.10.1261

Yu KH, Kohane IS (2019) Framing the challenges of artificial intelligence in medicine. BMJ Qual Saf 28:238-241. https://doi.org/ 10.1136/bmjqs-2018-008551

Yu KH, Beam AL, Kohane IS (2018) Artificial intelligence in healthcare. Nat Biomed Eng 2:719-731. https://doi.org/10.1038/ s41551-018-0305-z 
Zeng Y, Lu E, Huangfu C (2019) Linking Artificial Intelligence Principles. In: AAAI Workshop on Artificial Intelligence Safety. arXiv, Honolulu, Hawaii. https://arxiv.org/abs/1812.04814. Accessed 21 Jun

Publisher's Note Springer Nature remains neutral with regard to jurisdictional claims in published maps and institutional affiliations. 